


\section{THE ENABLING ENVIRONMENT FOR DISASTER RISK FINANCING IN PAKISTAN}

COUNTRY DIAGNOSTICS ASSESSMENT

JANUARY 2019 
(C) 2019 Asian Development Bank

6 ADB Avenue, Mandaluyong City, 1550 Metro Manila, Philippines

Tel +632632 4444; Fax +6326362444

www.adb.org

Some rights reserved. Published in 2019.

ISBN 978-92-9261-440-9 (print), 978-92-9261-441-6 (electronic)

Publication Stock No. TCS189269-2

DOI: http://dx.doi.org/10.22617/TCS189269-2

The views expressed in this publication are those of the authors and do not necessarily reflect the views and policies of the Asian Development Bank (ADB) or its Board of Governors or the governments they represent.

ADB does not guarantee the accuracy of the data included in this publication and accepts no responsibility for any consequence of their use. The mention of specific companies or products of manufacturers does not imply that they are endorsed or recommended by ADB in preference to others of a similar nature that are not mentioned.

By making any designation of or reference to a particular territory or geographic area, or by using the term "country" in this document, ADB does not intend to make any judgments as to the legal or other status of any territory or area.

This work is available under the Creative Commons Attribution 3.0 IGO license (CC BY 3.0 IGO)

https://creativecommons.org/licenses/by/3.0/igo/. By using the content of this publication, you agree to be bound by the terms of this license. For attribution, translations, adaptations, and permissions, please read the provisions and terms of use at https://www.adb.org/terms-use\#openaccess.

This CC license does not apply to non-ADB copyright materials in this publication. If the material is attributed to another source, please contact the copyright owner or publisher of that source for permission to reproduce it. $\mathrm{ADB}$ cannot be held liable for any claims that arise as a result of your use of the material.

Please contact pubsmarketing@adb.org if you have questions or comments with respect to content, or if you wish to obtain copyright permission for your intended use that does not fall within these terms, or for permission to use the ADB logo.

Corrigenda to ADB publications may be found at http://www.adb.org/publications/corrigenda.

Note:

In this publication, "PRs" refers to Pakistan rupees and "\$” refers to United States dollars.

On the cover (from left to right): Noor Khatoon crosses an improvised bridge near their former home in Todarwala village, Rajanpur district. Her family lived in six different houses before the floods hit and destroyed them all.

Locals passed by flooded National Highway N70, south of the city of Multan in Pakistan (photos by Gerhard Joren). 


\section{Contents}

Tables, Figures, and Boxes $\quad$ iv

Acknowledgments $\mathrm{V}$

Currency Equivalent vii

Abbreviations vii

Executive Summary viii

1. Introduction 1

$\begin{array}{lll}1.1 & \text { Background } & 1\end{array}$

1.2 Risk Layering Approach 2

1.3 Country Diagnostics Methodology 4

2. Public-Sector Disaster Risk Financing Landscape 9

2.1 Landscape Overview 9

$\begin{array}{lll}2.2 & \text { Diagnostic and Recommended Actions } & 12\end{array}$

3. Diagnostic on the Current Availability and Usage of Insurance, 15

Reinsurance, and Capital Markets for Disaster Risk Financing

3.1 Government Policy Gaps 16

3.2 Credibility of Private Sector Offering Risk Transfer Solutions 26

$\begin{array}{lll}3.3 & \text { Product Availability and Affordability } & 39\end{array}$

3.4 Social Protection $\quad 46$

4. The Rating Summary and Recommended Main Actions 48

4.1 Gaps in, and Recommendations for, Government Policy 49

4.2 Gaps in, and Recommendations for, Credibility in the Insurance Sector $\quad 49$ and the Capital Markets

4.3 Gaps in, and Recommendations for, Products $\quad 50$

4.4 Gaps in, and Recommendations for, Social Protection 51

4.5 Gaps in, and Recommendations for, Economic and Other Preconditions 51

4.6 Gaps in, and Recommendations for, Unlicensed Competition 51

Appendixes

$1 \quad$ Building Code of Pakistan (Fire Safety Provisions 2016) 53

2 Summary on National Disaster Management Authority Guidelines $\quad 55$

Minimum Standards of Relief to Be Provided to Persons Affected by Disaster

$3 \quad$ BISP Data Management and Sharing Protocols $\quad 57$

$\begin{array}{ll}\text { References } & 60\end{array}$ 


\section{Tables, Figures, and Boxes}

Tables

1 Agricultural Income in Pakistan, 2011-2012 to 2015-2016 17

2 Agricultural Area and Production $\quad 17$

3 Small Farm Holders, 2015-2016 17

4 Impact of 2005 Earthquake and 2010 and 2014 Floods on Pakistan's Agriculture $\quad 18$

5 Premium Rates on Agricultural Insurance $\quad 42$

\section{Figures}

1 Layered Approach to Disaster Risk Financing 3

2 W\&W Insurance, Reinsurance, and Capital Markets Solutions Development $\quad 7$

Framework-Hypothetical Example

3 Pakistan Disaster Risk Management Structure $\quad 10$

4 W\&W Insurance, Reinsurance, and Capital Market Solutions Development $\quad 15$

Framework Ratings Results for Pakistan

5 Insurance Penetration in Pakistan, 2010-2015 27

6 Rating Results for Pakistan 48

\section{Boxes}

1 Examining the Full Sovereign Disaster Risk Management Landscape 6

2 National Disaster Risk Management Fund $\quad 12$

3 Traditional Insurance Products Available in the Market 40 


\section{Acknowledgments}

T his report was prepared under the Technical Assistance (TA) 9007: Strengthening the Enabling Environment for Disaster Risk Financing (Phase 1). The TA was executed by the Asian Development Bank (ADB) in collaboration with the Government of Pakistan.

Charlotte Benson, Principal Disaster Risk Management Specialist, Climate Change and Disaster Risk Management Division, Sustainable Development and Climate Change Department (SDCC), ADB, and Arup Chatterjee, Principal Financial Sector Specialist, Finance Sector Group, Sector Advisory Service Cluster, SDCC, ADB, provided oversight direction and technical advice for the report. Shauzab Ali, Senior Project Officer (Financial Sector), and Mian Shaukat Shafi, Senior Project Officer, from the Pakistan Resident Mission provided support during the mission.

The report was produced by a team of ADB consultants comprising Rodolfo Wehrhahn, Team Leader, Insurance and Capital Market Regulatory Specialist (International Consultant); Nasreen Rashid, Disaster Risk Insurance Specialist (International Consultant); Mayur Ankolekar, Agricultural Insurance Specialist (International Consultant); Faraz Uddin Amjad, Insurance Industry Specialist (National Consultant); Kashmala Kakakhel, Disaster Risk Financing Specialist (National Consultant); and Maria Cristina Pascual, Project Coordinator (National Consultant).

The report benefited extensively from the kind interaction with many key organizations, to whom the team expresses great appreciation for their time and candid opinions.

\section{Government Agencies}

Agriculture Department of Punjab and Livestock Department of Punjab

Benazir Income Support Programme

Ministry of Climate Change

Ministry of Finance

Ministry of Planning, Development and Reforms, Economic Affairs Division

National Disaster Management Authority

Pakistan Agriculture Research Council

Pakistan Metrological Department

Postal Life Insurance

Provincial Disaster Management Authorities (Punjab and Sindh)

Securities and Exchange Commission of Pakistan

Sindh Livestock and Fisheries Department

State Bank of Pakistan 
Public Limited Companies and State-Owned Enterprises

National Insurance Company Limited

Pakistan Reinsurance Company Limited

Pakistan Stock Exchange Limited

State Life Insurance Corporation of Pakistan Limited

Zarai Taraqiati Bank Limited

Private Sector Organizations

Adamjee Insurance Company Limited

Al-Falah Insurance Company Limited

EFU General Insurance Limited

Ernst and Young

Insurance Association of Pakistan

Khushali Microfinance Bank Limited

Pakistan Banks Association

Pakistan Microfinance Investment Company Limited

Pakistan Microfinance Network

Pakistan Society of Actuaries

Premier Insurance Limited

Telenor Microfinance Bank Limited (formerly Tameer Microfinance Bank Limited)

Union of Small and Medium Enterprises

Other Development Organizations

National Rural Support Programme of Pakistan 


\section{Currency Equivalent}

\section{(as of 31 March 2017)}

$\begin{array}{lll}\text { Currency Unit } & - & \text { Pakistan rupee }(\mathrm{PRs}) \\ \text { PRs1.00 } & = & \$ 0.00954 \\ \$ 1.00 & = & \text { PRs104.77 }\end{array}$

\section{Abbreviations}

\begin{tabular}{|c|c|c|}
\hline $\mathrm{ADB}$ & - & Asian Development Bank \\
\hline BISP & - & Benazir Income Support Programme \\
\hline DRF & - & disaster risk financing \\
\hline DRM & - & disaster risk management \\
\hline GDP & - & gross domestic product \\
\hline IAIS & - & International Association of Insurance Supervisors \\
\hline IOSCO & - & International Organization of Securities Commissions \\
\hline NICL & - & National Insurance Company Limited \\
\hline PRCL & - & Pakistan Reinsurance Company Limited \\
\hline SECP & - & Securities and Exchange Commission of Pakistan \\
\hline SLIC & - & State Life Insurance Corporation \\
\hline
\end{tabular}




\section{Executive Summary}

T

This country diagnostics assessment reviews the current disaster risk financing (DRF) landscape and enabling environment in Pakistan with a focus on risk transfer instruments-insurance, reinsurance, and capital markets.

The assessment is based on a modified version of the W\&W Development Framework for accommodating international best practice and public and private sector stakeholders' inputs. This allows insight into existing or perceived demand and supply barriers shaping and, in part, restricting the development of an enabling environment for DRF in Pakistan. Within this framework, six areas relevant for the development of insurance and capital market solutions for DRF are reviewed: government policy; social protection policy; unlicensed competition; economic conditions; credibility of the insurance, reinsurance, and capital markets providers; and product appeal.

A risk-layered structure is proposed for the stimulation, development, and implementation of financially sustainable and scalable DRF strategies and solutions in Pakistan. The assessment identifies gaps and opportunities for enhancing the enabling environment for public sector DRF instruments, insurance, reinsurance, and insurance-linked securities through the capital markets. The table recommends improvements to the DRF enabling environment.

The diagnostics tool and a toolkit that describes the proposed enabling environment actions and their importance, the DRF tools and instruments of general use, including a glossary of technical terms, completes the suite of documents of this technical assistance. 
Table: Key Recommendations for Strengthening of the Enabling Environment for Disaster Risk Financing

\begin{tabular}{|c|c|c|c|}
\hline Recommendations & Responsible Body & Timing ${ }^{\mathrm{a}}$ & $\begin{array}{c}\text { Reference in } \\
\text { the Report }\end{array}$ \\
\hline $\begin{array}{l}\text { 1. Develop a comprehensive } \\
\text { national disaster risk financing } \\
\text { strategy following the risk } \\
\text { layered approach. }\end{array}$ & $\begin{array}{l}\text { National Disaster } \\
\text { Management Authority }\end{array}$ & Near term & Para. 32 \\
\hline $\begin{array}{l}\text { 2. Develop a comprehensive } \\
\text { disaster risk model and } \\
\text { mapping. }\end{array}$ & $\begin{array}{l}\text { National Disaster } \\
\text { Management Authority, } \\
\text { and Provincial Disaster } \\
\text { Management Authorities }\end{array}$ & Near term & Para. 33 \\
\hline
\end{tabular}
(1) Authorities

3. Quantify government-owned infrastructure and assets

Medium term Para. 34

Management Authority exposure to disasters and decide with the support of all line on their level of protection. ministries

4. Consider introducing compulsory catastrophe insurance for homeowners in disaster-prone urban areas.

5. Consider creating an Ministry of National Food agricultural insurance pool. Security and Research, Securities and Exchange Commission of Pakistan, and State Bank of Pakistan

6. Address concerns around definition of "agricultural index insurance" and definition of "calamity affected area."

Securities and Exchange Commission of Pakistan, and National Disaster Management Authority

7. Work on agricultural insurance Securities and Exchange products beyond the current government subsidized product.

\section{Commission of Pakistan,} and Insurance Association of Pakistan

8. Seek support from international Ministry of National Food organizations and engagement with global insurers to gain access to modern insurance related technology for agricultural insurance.

9. Carry out an assessment against the International Association of Insurance Supervisors Insurance Core Principles and against the International Organization of Securities Commissions principles.

10. Carry out a detailed assessment of the reserve adequacy, asset quality and risk management, including stress testing.
Ministry of National Food
Security and Research, and Insurance Association of Pakistan

\section{Medium term Paras. 58, 59, and 60}

Medium term Para. 51

Near term Para. 61

Securities and Exchange $\quad$ Medium term Para. 105
Commission of Pakistan
Near term Para. 61

Near term Para. 63

Medium term Para. 105
Ministry of Commerce, $\quad$ Near term $\quad$ Paras. 106, 107
National Insurance Company
Limited, and Pakistan
Reinsurance Company
Limited continued on next page 
Table continued

\begin{tabular}{|c|c|c|c|}
\hline Recommendations & Responsible Body & Timing $^{\mathrm{a}}$ & $\begin{array}{l}\text { Reference in } \\
\text { the Report }\end{array}$ \\
\hline $\begin{array}{l}\text { 11. Continue to develop customized } \\
\text { insurance awareness programs } \\
\text { on disaster risk insurance } \\
\text { through public-private } \\
\text { endeavors. }\end{array}$ & $\begin{array}{l}\text { National Disaster } \\
\text { Management Authority, } \\
\text { Insurance Association of } \\
\text { Pakistan, and Securities } \\
\text { and Exchange Commission } \\
\text { of Pakistan }\end{array}$ & Medium term & Para. 108 \\
\hline $\begin{array}{l}\text { 12. Consider insurance linked } \\
\text { securities, including catastrophe } \\
\text { bonds, as additional disaster } \\
\text { risk financing instruments. }\end{array}$ & $\begin{array}{l}\text { Economic Affairs Division, } \\
\text { and Securities and Exchange } \\
\text { Commission of Pakistan }\end{array}$ & Medium term & Para. 129 \\
\hline $\begin{array}{l}\text { 13. Consider private partnerships } \\
\text { led by the public-sector insurers } \\
\text { and State Life Insurance } \\
\text { Corporation taking advantages } \\
\text { of their vast agency distribution } \\
\text { network to promote the uptake } \\
\text { of microinsurance. }\end{array}$ & $\begin{array}{l}\text { Ministry of Commerce, } \\
\text { Insurance Association of } \\
\text { Pakistan, National Insurance } \\
\text { Company Limited, and State } \\
\text { Life Insurance Corporation }\end{array}$ & Medium term & Paras. 79, 135 \\
\hline
\end{tabular}

a "Near term" is within 1 year. "Medium term" is 1-3 years.

Source: Asian Development Bank. 


\section{Introduction}

\subsection{Background}

1. Disasters delay long-term development and hamper efforts to reduce poverty in the developing member countries of the Asian Development Bank (ADB). Disasters set back development, directly damaging and destroying infrastructure and disrupting related economic activities and the provision of services. They place countries on lower long-term growth trajectories, push vulnerable communities deeper into poverty, and force adjustments in both short- and longer-term development targets and goals. They can place significant fiscal strain on governments, businesses, and individual households, particularly if financial preparedness arrangements are limited. Delays and shortages in the availability of funding can significantly exacerbate the consequences of direct physical losses, extending the time to rebuild. Government officials, policymakers, and insurance regulators from developing Asian countries have therefore expressed the need to strengthen their financial preparedness for disasters, smoothing the cost of disasters over time and ensuring timely availability of post-disaster funding. ${ }^{1}$ A strong enabling environment for disaster risk financing (DRF), including for the stimulation of commercial risk transfer markets, is a priority prerequisite for achieving this.

2. Enhanced financial preparedness for disasters an ADB priority. The ADB Technical Assistance (TA) project, Strengthening the Enabling Environment for Disaster Risk Financing (ADB 2015) under which this document is prepared, is consistent with ADB's Operational Plan for Integrated Disaster Risk Management, 2014-2020, which supports "the development of DRF instruments and wider DRF strategies for households, businesses, and governments, enhancing the public and private financial management of residual disaster risk (ADB 2014). It is also consistent with the 2017 Review of the 2011 Financial Sector Operational Plan (ADB 2017c), which calls for building capabilities in emerging and innovative finance areas such as DRF.

3. ADB's holistic approach to DRF is reflected in this TA. ADB strongly advocates an integrated approach to disaster risk management (DRM), seeking to strengthen disaster resilience both through disaster risk reduction and the enhanced management of residual risk. ADB is seeking to enhance financial preparedness for disasters as part of broader efforts to strengthen disaster resilience. It is doing so in close coordination with governments, global

1 For example, these views were expressed at two events that ADB organized in partnership with the Organisation for Economic Co-operation and Development (OECD) to exchange knowledge and practices on financial protection against disaster risks among officials and experts from ADB, Asia-Pacific Economic Cooperation, Association of Southeast Asian Nations, governments in Asia and elsewhere, and the insurance industry. These events comprised (i) an ADB-OECD Forum on Disaster Risk Financing for Inclusive Development, 15-16 September 2015, Manila, Philippines; and (ii) an ADB-OECD Global Seminar on Disaster Risk Financing: Developing Effective Approaches to the Financial Management of Disaster Risks, 17-18 September 2015, Kuala Lumpur, Malaysia. 
and regional DRF initiatives, ${ }^{2}$ standard-setting bodies such as the International Association of Insurance Supervisors (IAIS), International Organization of Securities Commissions (IOSCO), the Basel Committee on Banking Supervision, the Islamic Financial Services Board, the Financial Stability Institute, and the insurance industry. Disaster risk reduction efforts should be the first consideration in addressing disaster risk, tackling the root causes of the issue. DRF solutions should also conform to international financial standards and be designed around the context of broader disaster resilience, financial stability, and financial inclusion, incorporating incentives for disaster risk reduction. This approach should lead to the development and implementation of financially sustainable, scalable DRF strategies and solutions. ADB applies a risk-layered approach to support the appropriate selection of DRM options, including DRF instruments (section 1.2).

4. This country diagnostics assessment identifies areas of improvement to promote an enhanced enabling environment for DRF in Pakistan. The country diagnostic is expected to facilitate the development and implementation of appropriate instruments for different layers of risk. It identifies areas of improvement to enhance the enabling environment for public sector DRF solutions ${ }^{3}$ as well as for insurance, reinsurance, and capital market solutions.

5. Recommendations based on the assessment are comprehensively presented at the end of the section of each axis. The recommended series of activities and measures to enhance the enabling environment for key public sector DRF instruments as well as insurance, reinsurance, and capital markets solutions.

\subsection{Risk Layering Approach}

6. Disaster resilience begins with risk reduction, that is, acting to reduce levels of loss in the event of natural hazards. However, disaster risk cannot be eliminated, so investments in financial preparedness for disasters needs to be enhanced as well, seeking to ensure that sufficient financing is available to support timely relief, early recovery, and reconstruction efforts.

7. Governments can draw on an array of instruments to support enhanced financial preparedness. These instruments are ideally applied using a risk-layering approach, breaking disaster risk down according to the frequency of occurrence of different types of hazard events of varying severity and associated levels of loss, and designing bundles of instruments targeting differentiated layers of risk (ADB 2014). Governments should seek to select the most appropriate instruments for each layer of loss based on a range of factors, including the scale of funding needed, the speed with which disbursement is required, and the relative cost-effectiveness of alternative instruments for specific layers of risk.

2 Vulnerable Twenty (V20) Group; Disaster Risk Financing and Insurance Program of the World Bank, Market Global Practice and Global Facility for Disaster Reduction and Recovery; Pacific Disaster Risk Financing and Insurance Program. APEC/OECD Promoting the G20/OECD Methodological Framework for Disaster Risk Assessment and Risk Financing.

3 The stakeholder consultations of 2017 updated 2016 World Bank assessment, which considerably informed this work (World Bank 2015b). 
Figure 1: Layered Approach to Disaster Risk Financing

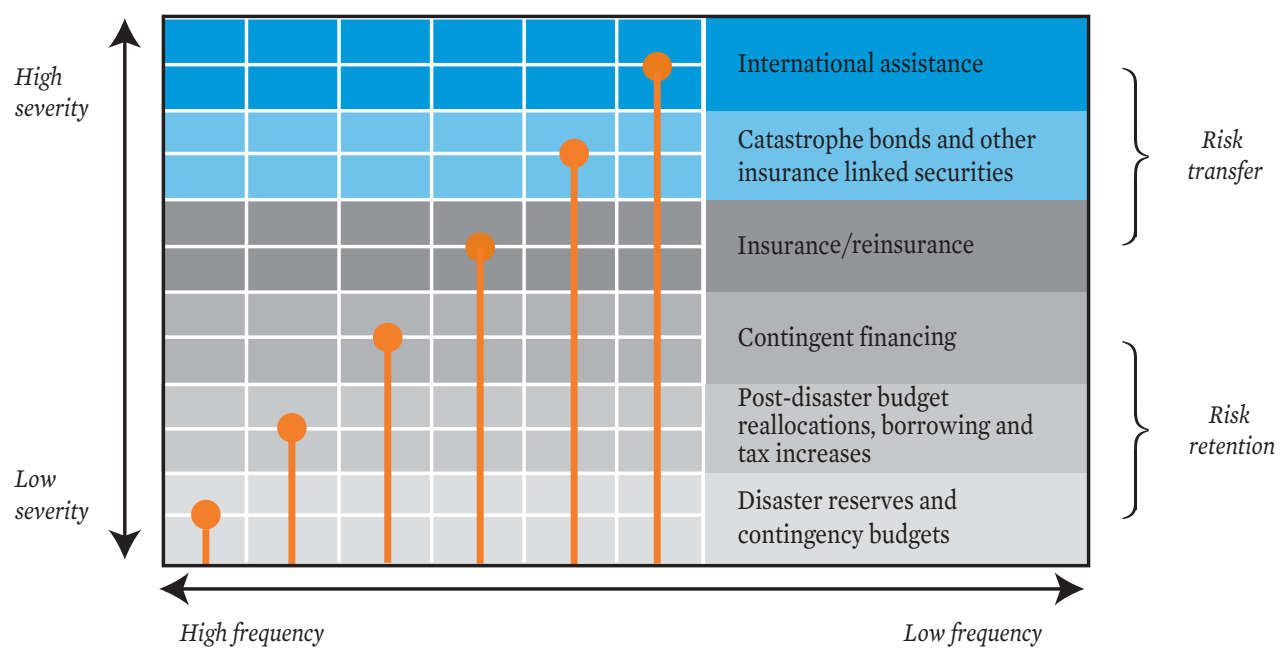

Source: Asian Development Bank (2013).

8. DRF instruments for residual risk begin with risk retention instruments for more frequent, less damaging events (Figure 1). These include annual contingency budget allocations, disaster reserves, and contingent financing arrangements, all of which are put in place before disasters strike. After disaster strikes, governments can also reallocate budgets, increase borrowing, and raise taxes to provide additional resources.

9. Market-based risk transfer solutions provide more cost-efficient financing for medium-level risks, generating higher levels of loss but less frequently. These include insurance and insurance-linked securities (ILS), such as catastrophe bonds, and are taken out in anticipation of potential disasters. In the event of major disasters, governments also appeal to the international community for assistance.

10. DRF is not only a government responsibility, the private sector and individuals should be encouraged and enabled to share in this. A similar risk-layering approach is applicable. Decisions on reduction, retention, and transfer of disaster risk should be made within the structure of this broader framework, selecting appropriate instruments for each layer of risk. The insurance sector is called to play an important role in this by developing tailor-made products suitable to Pakistan.

11. The availability and assortment of instruments selected for a DRF strategy depend on a range of factors. The most appropriate bundle of instruments depends on the scale of resources required at each layer of loss relative to the scale of resources each instrument can facilitate access to; the speed with which funds are required relative to the disbursement speed of each instrument; the marginal cost of each instrument; individual country circumstances, including prevailing macroeconomic circumstances; the scale of potential events relative to gross domestic product (GDP); government economic, fiscal, and monetary goals and objectives; access to international finance markets; and the marketbased cost of borrowing (ADB 2013). For example, if probable maximum losses from extreme 
events are low relative to GDP, then a country is better able to retain risk. A country with low indebtedness can rely more on post-disaster borrowing than one with a higher level. The effectiveness of disaster risk transfer instruments also depends crucially on the availability of well-developed and sound domestic insurance and capital market sectors. Among other issues, the cultural and religious dimensions are important, while it should be noted that government policy could potentially crowd out the private insurance sector.

\subsection{Country Diagnostics Methodology}

\subsubsection{Diagnostics Tool}

12. A diagnostics tool was developed to conduct both the Pakistan diagnostics assessment and diagnostics for three additional countries under the TA. The tool, a series of questions, seeks to identify gaps between international best practice and the country situation. It assesses the current state of the enabling environment for DRF in each country and gaps and opportunities for enhancement.

13. The diagnostics tool draws on a modified version of the "W\&W Development Framework." This framework was refined to provide a methodology for assessing the DRF landscape and its enabling environment. It focuses on six areas of relevance for the development of disaster insurance and capital market solutions:

(i) Government policy in the development of risk transfer instruments for DRF, including the introduction of mandatory insurance protection, risk-pooling structures, and ILS, ${ }^{5}$ pertinent regulations, and the creation of a level playing field for insurance, reinsurance, and capital market activities.

(ii) Economic conditions and other support functions that influence the decision for retaining the risk rather than purchasing insurance, reinsurance, and capital markets products (e.g., legal framework, data availability).

(iii) Disaster risk product availability and affordability, including products for corporates, individual households, and low-income populations.

(iv) Credibility of the private sector offering risk transfer solutions that cover aspects such as the regulatory environment, the solvency of risk carriers, the reputation of insurance and capital markets, and the availability of infrastructure (e.g., financial transaction platforms and support from professionals such as actuaries, risk assessors, auditors, dealer brokers, and stockbrokers).

4 The W\&W Development Framework has been used on several occasions by Rodolfo Wehrhahn, one of the assessors, to determine barriers to an enabling environment in work done for ADB, the International Monetary Fund, and the World Bank. The relevant areas for an enabling environment as determined in this framework follow from Wehrhahn (2010).

5 ILS bonds, including catastrophe bonds and other risk-linked securitization, represent assets whose value is largely driven by the occurrence of events not correlated to the financial markets, allowing for a high degree of diversification. With an ILS bond the investor is exposed to a well-defined catastrophic or insurable event in addition to the credit risk of the issuer. For this additional exposure, investors are compensated with higher coupons, but if no covered event occurs during the risk period the bonds are redeemed at $100 \%$ of face value. When a covered event meets the thresholds in the risk transfer contract, investors stand to lose coupon payments and/or a percentage of the principal. The redemption price of the bonds is reduced accordingly. For more details, see the companion report entitled "Toolkit for Insurance, Reinsurance and Capital Market Solutions for Disaster Risk Financing." 
(v) Social protection policy, recognizing that low-income populations should enjoy social protection or support in obtaining insurance coverage while insurance solutions for people that can afford the premium should not be crowded out, and exploring the degree to which social protection complements or crowds out marketbased solutions.

(vi) Unlicensed competition, recognizing that insurance credibility and resilient insurance providers are important, and examining licensing and supervision of insurance providers by the regulator.

14. The diagnostics tool generates an overview of current policies and mechanisms for DRF. It identifies enabling conditions for effective use of well-established DRF instruments and existing related barriers or gaps; sets policy priorities for implementing reforms and introducing new DRF instruments; and provides the basis for new or deeper engagement on DRF by governments, regulators, and development partners as part of broader DRM and/or public financial management dialogue. The findings of the diagnostic can feed directly into the development of DRF strategies to enhance financial preparedness.

15. The tool consists of questions to identify gaps between international best practice and current country practice. It also identifies enabling conditions for the effective use of well-established DRF instruments and existing related barriers or gaps.

16. The diagnostics tool focuses on assessment of disaster risk transfer instruments, covering sovereign and nonsovereign instruments. Governments can play an important role in providing an adequate enabling environment for nonsovereign insurance, such as homeowner and commercial property insurance, business interruption cover, and crop insurance. In the process, they can reduce the contingent liability falling on government in the event of a disaster. Tools used for self-insurance or disaster risk retention by the government are mentioned, but not addressed in any depth, as these are covered in a complementary tool developed in ADB and the World Bank (2017) (Box 1).

17. A fuller description of the tool, including the questions under each of the six areas of relevance, is presented in a companion document produced under the TA (ADB forthcoming). The document also presents a generic toolkit for disaster insurance, reinsurance and capital market solutions, including a glossary of technical terms, focusing on actions to strengthen the enabling environment to support potential DRF instruments.

\subsubsection{Application of the Diagnostics Tool}

18. The diagnostics tool is used to determine and confirm DRF practices and gain insight into existing or perceived barriers hindering the development of DRF tools. The diagnostics tool is applied through a combination of desk work, stakeholder questionnaires, interviews, and group discussion. This wide-ranging approach is taken to accommodate the international good practice of countries with successful results and expert judgment on the actions needed to better enable effective use of DRF instruments.

The basic steps are as follows:

(i) As a starting point, background information on the DRF strategy of the country is gathered. The information is drawn from extensive publications, government 


\section{Box 1: Examining the Full Sovereign Disaster Risk Management Landscape}

The Asian Development Bank-World Bank disaster risk financing diagnostic assesses levels of financial protection against disasters to identify opportunities for enhancement. It includes questions for ministries of finance drawn upon to extend the country analyses done under the current TA to build a fuller picture of the state of sovereign disaster risk financing arrangements, including risk-retention mechanisms. The questions cover the following issues:

1. Assessment of fiscal shocks associated with disasters:

(i) contingent liability of the government,

(ii) fiscal risk assessment of disaster shocks, and

(iii) public disclosure of disaster-related fiscal exposure.

2. Ex ante disaster risk financing:

(i) annual contingency budget,

(ii) dedicated budget lines for disaster risk reduction,

(iii) dedicated disaster reserve funds,

(iv) line agency funding,

(v) contingent financing arrangements,

(vi) insurance of public assets,

(vii) any other forms of sovereign insurance, and

(viii) risk transfer arrangements through capital markets.

3. Ex post disaster risk financing:

(i) post-disaster budget reallocations,

(ii) external assistance, and

(iii) other ex post mechanisms.

Source: Asian Development Bank and World Bank (2017).

websites, insurance and reinsurance industry documents, and capital market analyses.

(ii) The background information is then complemented using extensive questionnaires with open questions on areas relevant to the DRF strategy and instruments used in the country. These questionnaires, integral to the diagnostics tool, are sent to relevant stakeholders for their inputs. The insights gained are critical for a robust assessment, and, as such, questions to the stakeholders are explained carefully, stressing the importance of providing comprehensive and open answers.

(iii) On-site interviews take place with selected stakeholders from both the public sector and the insurance, reinsurance, and capital market stakeholders, including actuaries, rating agencies, brokers, and auditing firms. These interviews enhance and complete the information gathered through the desk analysis and the questionnaire responses.

(iv) The comprehensive information is then analyzed and gaps between international best practice and current practices identified.

(v) The recommended actions are discussed with the stakeholders and the feasibility and relevance of these recommendations are confirmed before the country diagnostic is finalized.

(vi) Implementation of the recommendations should follow. 
19. There is nonetheless an expectation that every stakeholder will not respond to all questions. Experience shows that the questionnaire will provide wide ranging responses, including contradicting statements, and some questions will remain unanswered. The assessors have judge and filter the information to draw conclusions, but these conclusions are then verified with stakeholders repeatedly, and only after verifications are recommendations provided.

\subsubsection{Presentation of the Diagnostic Results}

20. The country diagnostic reports begin by presenting findings on the broad public sector DRF landscape, including related recommendations. The results of the diagnostic analysis are then presented and finally summarized in a spider diagram depicting country scoring for each of the six areas of relevance for the development of disaster insurance and capital market solutions (Figure 2). For each area, an ideal, a realistic, and the current state of the environment are depicted.

21. The ideal enabling conditions for the development of insurance, reinsurance, and capital markets solutions for each of the six areas are defined. The assessors define this environment based on international best practice and expert judgment. This step considers the political, cultural, and religious contexts of the marketplace as well as international best practice.

Figure 2: W\&W Insurance, Reinsurance, and Capital Markets Solutions Development Framework-Hypothetical Example

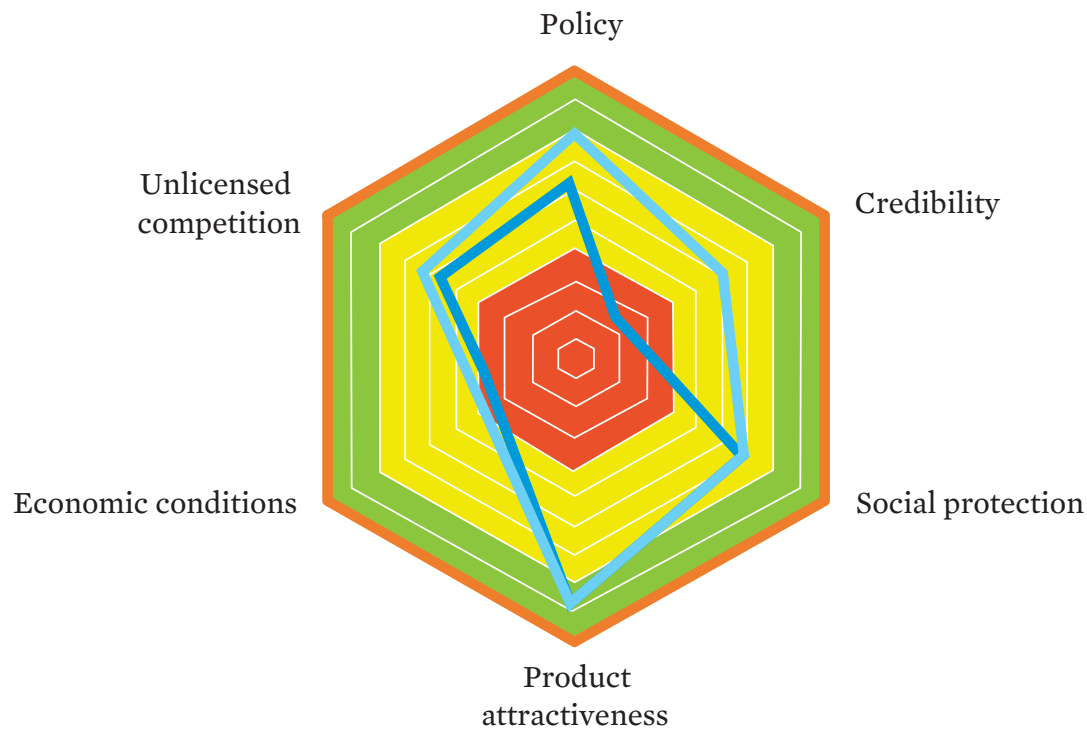

Enabling environment DRF IRCM existing environment

DRF IRCM realistic achievable environment

$\mathrm{DRF}$ = disaster risk financing; $\mathrm{IRCM}$ = insurance, reinsurance, and capital market.

Source: Asian Development Bank. 
22. A reality check defines the next best insurance, reinsurance, and capital markets solutions enabling environment that can be achieved. The ideal enabling environment may never be achieved, so a realistic or aspirational enabling environment for each of the six areas is also determined. This is the best achievable environment and is developed drawing on local expertise gained through extensive stakeholder consultation and analysis of the questionnaires to identify likely impediments to achievement of the ideal enabling environment. The ideal and realistic enabling environments will not necessarily differ significantly, resulting in overlap of both, as Pakistan proves (para. 36).

23. The current environment is then populated. Using local expertise and comments from relevant national stakeholders, including government authorities, private sector providers, and professional bodies, the current environment for each of the axes is determined.

24. The methodology used depicts the gaps between the current enabling environment for disaster insurance, reinsurance, and capital markets solutions and the ideal and realistic alternatives. The comparison enables ready identification of areas for action, leading to the development of a strategy and road map for removal of the gaps. Actions to address the gaps should be prioritized depending on the scale of need and reflecting timeframes for completion. Urgent actions are recommended to strengthen the enabling environment in the areas of relevance achieving scores of four or below (color red); mediumterm actions are needed for scores between four and six (yellow); and no immediate actions are required for higher scores (green). Where the realistic enabling environment differs from the ideal scenario, that difference is considered when determining the urgency of the needed actions. The absolute scores have no further meaning and should not be used for crosscountry comparisons. 


\section{Public-Sector Disaster Risk Financing Landscape}

\subsection{Landscape Overview}

25. Pakistan faces substantial disaster risk. The country is increasingly exposed and vulnerable to various natural hazards, particularly floods, cyclones, droughts, and earthquakes. Increasing natural hazard events over the last 15 years have caused significant loss of life, economic damage, and reversal of development gains. Floods have caused most physical damage, with the most significant floods in history occurring in 1950, 1992, 1998, 2010, 2011, and 2014. Just the latter three events affected more than 30 million people, with damage and losses exceeding $\$ 14$ billion. Parts of the country also face significant seismic risk. A major earthquake in 2005 caused more than 73,000 deaths and $\$ 5$ billion in losses. In addition, the country faces tropical cyclone risk, with a major cyclone event in 2007 affecting 2.5 million people, and droughts, including a drought in 2014-2015 that affected more than 3 million people, severely impacting the livelihoods of poor and vulnerable populations and resulting in mass migration. The country is among the 10 most vulnerable to the impacts of extreme weather events (Germanwatch 2015).

26. Financing disasters is a challenge for the Government of Pakistan. The government estimates the economic impact due to flooding alone is between $3 \%-4 \%$ of GDP annually. ${ }^{6}$ From 2005 to 2015 , the financial losses due to disasters triggered by natural hazards amounted to $\$ 18$ billion (World Bank 2015c). World Bank simulations predict that a major flood event, occurring on average once every 100 years, could cause losses in excess of $\$ 15.5$ billion, around $7 \%$ of national GDP or almost $40 \%$ of the federal budget in annual probability. There is a $1 \%$ chance in any year that a major event of this size will occur (World Bank 2015c).

27. The Government of Pakistan has taken significant steps to improve the management of disaster risk over the past 10 to 15 years, both to tackle underlying disaster risk and improve post-disaster response. The government historically took a largely response-oriented approach to disasters, reacting as and when they occurred. The country had no permanent capacity to effectively respond or proactively improve its resilience to disasters. However, the 2005 earthquake led to a paradigm shift in DRM policy and strategy. The government established the Earthquake Reconstruction and Rehabilitation Authority immediately after the earthquake through a special ordinance to coordinate, plan, monitor, and oversee reconstruction. And in 2007, it approved a National Disaster Management Ordinance, establishing the National Disaster Management Authority and Provincial Disaster Management Authorities, and a National Disaster Risk Management Framework, introducing a proactive and comprehensive approach to DRM, including risk reduction, preparedness, response, and recovery, and providing strategic direction (Figure 3). A National Disaster Management Act was subsequently passed in 2010. The 18th amendment of the Constitution

6 Budget estimate taken from Government of Pakistan (2014). 


\section{Figure 3: Pakistan Disaster Risk Management Structure}

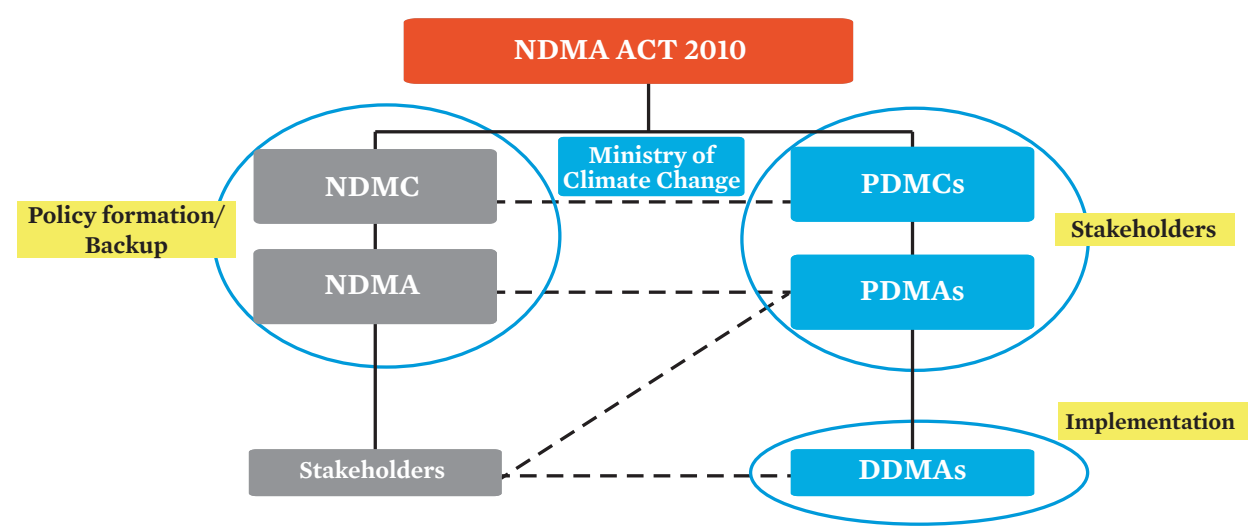

DDMA = District Disaster Management Authorities; NDMA = National Disaster Management Authority, NDMC = National Disaster Management Commission, PDMA = Provincial Disaster Management Authorities, PDMC = Provincial Disaster Management Commissions.

Source: National Disaster Management Authority (2010).

in 2011 devolved DRM functions to the provinces. A National Disaster Management Plan was approved in 2013, replacing the National Disaster Risk Management Framework and outlining investment needs. A National Disaster Risk Reduction Policy was also approved in 2013. The Fourth National Flood Protection Plan was approved in 2016, with the National Disaster Management Plan, outlining some $\$ 3$ billion in investment needs. There are plans to set up a National Disaster Management Fund for the federal capital, for which the government approved a budget of PRs150 million in 2017.

28. In addition to the above, a wide range of bodies and programs are involved in DRM. The Pakistan Meteorological Department, Pakistan Agriculture Research Council, Ministry of National Food Security and Research, Pakistan Council of Research in Water Resources, Water and Power Development Authority, National Space Agency of Pakistan, Global Change Impact Study Centre, and Pakistan Forest Institute provide policy makers with early warning information which supports disaster risk planning and management. ${ }^{7}$ In addition to National Disaster Management Authority, the Federal Flood Commission, the Provincial Irrigation Departments, the Armed Forces, the Maritime Security Agency, the Pakistan Red Crescent Society, and the National Highway Authority support emergency response efforts.

29. However, the country continues to face funding challenges for disaster risk reduction and disaster response, and the heavily decentralized approach to DRF complicates challenges in enhancing DRM. Federal and provincial governments have highly limited ex ante financing instruments in place for post-disaster response. The National Disaster Management Act of 2010 established a National Disaster Management

7 Any extreme weather related early warning information is provided by the Pakistan Meteorological Department. Slow onset weather disaster-related research (like drought) are generally carried out by the Global Change Impact Study Centre or Pakistan Agriculture Research Council. 
Fund administered by the federal government and separate disaster management funds administered by each of the provincial governments. The act also provided an overview of the types of expenditure incurred by the federal government which could be covered by this fund. This includes provision of shelter, food, drinking water, medical cover and sanitation, special provisions for vulnerable groups, discretionary assistance for loss of life, and assistance for damage to housing and restoration of livelihoods (Government of Pakistan 2010). However, in practice, significant work remains to be accomplished in operationalization of the funds, adequate provision of financing mechanisms, and standardization of procedures across provinces. The mechanisms through which disasters are financed vary by province, depending on the administrative system and the ready availability of funds. The federal government has only limited contingency funding for response to national emergencies, in the order of $\$ 15$ million- $\$ 20$ million. It relies on post-disaster budgetary reallocations and, for major disasters, primarily on international assistance to fund response efforts. Penetration of insurance markets is also highly limited. For instance, insured losses because of the 2010 floods amounted to $\$ 100$ million, equivalent to just $1 \%$ of total damage and losses, implicitly placing an additional burden on government. The government has highly limited sovereign risk transfer mechanisms, with only $30 \%$ of public assets insured according to the State Life Insurance Corporation (SLIC) official interviewed for assessment, and that only during the construction phase. Moreover, federal and provincial governments lack any broader financial strategy to manage the fiscal consequences of disasters and it remains difficult for the government to analyze the financing requirements and gaps for meeting relief, recovery, and reconstruction needs.

30. Development partners are supporting the country in overcoming these funding challenges. Many of Pakistan's development partners have engaged long-term in DRM in the country, focusing on post-disaster response. A series of major disaster events over the past decade, in particular since 2010, has increased the emphasis on disaster risk reduction and preparedness, including financial preparedness. In financial preparedness, ADB approved a \$200 million loan for Pakistan in December 2016 to support the establishment of a National Disaster Risk Management Fund, under which support will be provided for a range of DRM activities including disaster risk modelling, investments in disaster risk reduction, the development of a national DRF strategy, and the design and piloting of several insurance instruments (Box 2). The World Bank undertook a broad fiscal disaster risk assessment of the country in 2015 (World Bank 2015c), and, building on this, is supporting the establishment of DRF strategies and DRM funds at the provincial level. In October 2017, the InsuResilience Investment Fund agreed to acquire a significant minority stake in Lahore-based Asia Insurance, a general insurer offering agriculture insurance to over 100,000 farmers in Pakistan, to extend the insurance coverage of poor and vulnerable households. ${ }^{8}$ The Climate Development Knowledge Network, which supports developing country decision-makers in designing and delivering climate compatible development, is supporting the National Disaster Management Authority in setting up the Disaster Risk Insurance Framework for vulnerable communities in Pakistan.

8 Asia Insurance Review. 2017. Pakistan: InsuResilience Fund Takes 25\% Stake in Insurer. 11 October. http://www3 .asiainsurancereview.com/News/View-NewsLetter-Article/id/40525/Type/eDaily/Pakistan-InsuResiliencefund-takes-25-stake-in-insurer/1/sid/96572?utm_source=News\&utm_medium=Email\&utm_campaign=AIR_ eDaily. The InsuResilience Investment Fund was set up by the German Development Bank KfW on behalf of the German Ministry for Economic Cooperation and Development. 


\section{Box 2: National Disaster Risk Management Fund}

The National Disaster Risk Management Fund was established in 2017 as a governmentowned not-for-profit association to reduce Pakistan's socioeconomic and fiscal vulnerability to natural hazards, climate variability and climate change.

The government has contributed $\$ 25$ million to the fund and Asian Development Bank (ADB) a \$200 million financial intermediary loan and piggybacked capacity development technical assistance to fast-track implementation. Further ADB assistance is proposed for 2019 and 2020. Additionally, bilateral donors have provided co-financing grants, and other donors have expressed interest in contributing.

The fund is incorporated under section 42 of the 1984 Companies Ordinance and intended to provide financial and technical support to government and nongovernment partners to implement the National Disaster Management Plan and the National Flood Protection Plan-IV.

ADB loan proceeds have been used, in part, to capitalize the National Disaster Risk Management Fund through the establishment of a $\$ 123.3$ million endowment fund to ensure the Fund's long-term financial viability and sustainability. The remainder of the loan will be on-granted through the Fund for disaster risk reduction (DRR) and disaster risk financing (DRF) purposes. The DRR component will provide funding through matching grants of up to $70 \%$, with interventions carried out by public sector entities or nongovernment organizations at the federal, provincial, district or community level. The DRF activities include (i) disaster risk modelling, (ii) the development of a national DRF strategy, and (iii) the design and piloting of several DRF products.

Source: Asian Development Bank (2016).

\subsection{Diagnostic and Recommended Actions}

31. A sustainable plan is needed to ensure the National Disaster Management Fund and provincial funds are adequately provisioned for disaster response. As the World Bank states

while the federal and provincial governments recognize the need for allocating resources in their budgets for disaster response prior to a disaster, they lack the technical basis to determine such allocations. At present post-disaster expenditures are financed from contingent and supplementary budgets during the relief and recovery phases and from the annual Public Sector Development Program during the reconstruction phase. The inaccessibility of data on the underlying hazards and their past and possible future financial implications is one barrier to the process of informed ex ante provisioning of funds. A development of technical capacity and necessary tools to quantify likely needs for disaster related expenditure would help the government to both: (i) determine appropriate allocations through the budget; 
and (ii) to also explore and make informed proposals for possible sources of financing outside of the budget. ${ }^{9}$

32. An effective country DRF strategy should be developed based on detailed knowledge of the country's disaster risk. Some district and city multi-hazard vulnerability and risk assessments have been conducted, with more planned. However, no comprehensive stochastic assessment of disaster risk is now available for Pakistan. Information is scattered across different ministries and other institutions and lacks sufficient detail on the probability of various natural hazards striking different areas of the country, by type or intensity, to support development of a national DRF strategy. Some historical loss databases are available, but the quality and length of records is too limited for actuarial modelling of disaster risk. ${ }^{10}$ Likewise, the insurance industry does not have consolidated risk exposure accumulation statistics. A detailed national hazard map (earthquake, flooding, and drought) does not exist, public and private infrastructure and other assets exposed to natural hazards have not been quantified, and weather-related data is limited. This type of information would be beneficial to the whole economic sector to facilitate disaster-risk-informed decision making. The recently published ADB report, Climate Change Profile of Pakistan (ADB 2017b)-a comprehensive overview of expected climate impacts on agriculture, water, energy, transport, health sectors, and coastal areas-could be useful in this context.

33. The government should develop a comprehensive disaster risk model and mapping with sufficient granularity to support the development of an effective DRF strategy. Armed with enhanced information on the different probabilities of various types and intensities of natural hazard, the government should develop a comprehensive national DRF strategy following a layered DRF approach (section 1.2). This is expected to be addressed through the recently established National Disaster Risk Management Fund, which has indicated support for the development of open platform disaster risk modelling and the development of a national DRF strategy as one of its first areas of focus of work (section 2.1).

34. Mapping and valuation of provincial and federal government-owned infrastructure and other assets should be carried out. It is reported that a large segment of government property remains self-insured. Self-insurance could be the right risk management tool. However, the government's decision whether to retain the risk should be taken after carrying out a proper risk and exposure analysis. Mapping and valuation of provincial and federal-government-owned infrastructure and other assets should be carried out. The analysis should provide sufficient detail to allow robust assessment of disaster risk. It should include collation of data on the location of buildings and other critical infrastructure, use, age, structural type, construction materials, roof configuration, number of stories, and local geology.

9 World Bank. 2015. Fiscal Disaster Risk Assessment Options for Consideration. Washington, D.C.: The World Bank. page 8.

${ }^{10}$ While some information is available with the National Disaster Management Authority, most post-disaster damage and loss information is compiled by the Provincial Disaster Management Authorities. This reflects, in accordance with the 18th amendment, that provincial governments are expected to fund a major part of disaster response themselves. Hence, the provincial government finance departments hold information about the damage and losses funded by provincial governments. However, the provincial level data excludes a significant proportion of private sector losses (insured and uninsured). 
35. Effective DRM actions should be put in place for public assets. Following the stocktaking and exposure analysis recommended in the previous paragraph, appropriate DRM actions should be undertaken. As a starting point, a subset of public property focusing on key uninsured and lifeline infrastructure, ${ }^{11}$ should be considered. The program for proper DRM should then aim to reduce disaster risk to retention levels where insurance would be available at a reasonable cost.

11 The 2013 National Disaster Risk Reduction Policy of Pakistan uses the term "key-infrastructure and life-line" and defines it as those facilities, structures, and services whose disruption or destruction would seriously affect peoples' lives and livelihoods, including those whose functioning is crucial in a post-disaster situation, that is, educational and health facilities; electricity, transport and communication; important state-owned buildings; water supply and sanitation; and irrigation systems. 


\section{Diagnostic on the Current Availability and Usage of Insurance, Reinsurance, and Capital Markets for Disaster Risk Financing}

36. Enhanced use of disaster risk transfer instruments in Pakistan requires significant improvement in the associated insurance, reinsurance, and capital market enabling environment. Using the diagnostics tool presented in section 1, several areas of improvement in the use and development of disaster risk transfer instruments have been identified in the six areas of relevance for the development of disaster insurance, reinsurance, and capital markets solutions (Figure 4). It should be noted that Pakistan's ideal scenario coincides vastly with the achievable scenario. For this reason, the assessors decided to focus on the ideal scenario and formulate recommendations to achieve that enabling environment. Also, given the crosscutting nature of the economic and other preconditions, the related recommendations for this axis have been incorporated into the recommendations for the other axes. Similarly, the recommendations relating to unlicensed competition are included in the discussion on the social protection axis, in this case reflecting the strong focus of the former on the low-income

Figure 4: W\&W Insurance, Reinsurance, and Capital Market Solutions Development Framework Ratings Results for Pakistan

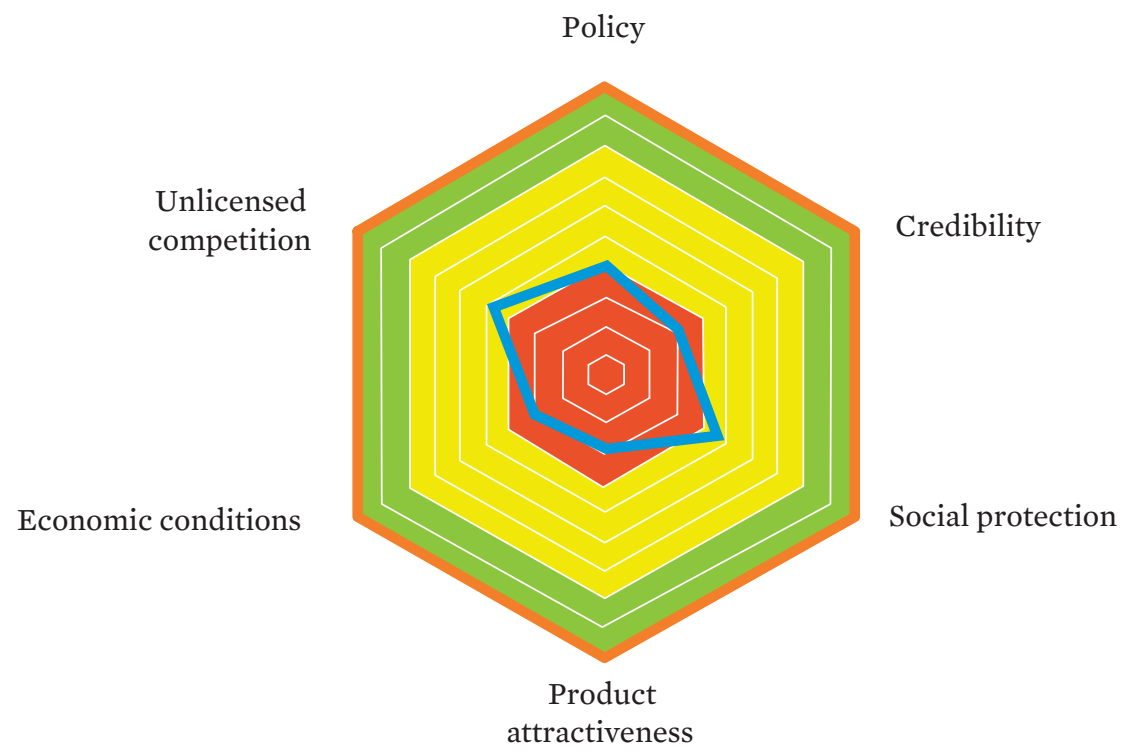

$\longrightarrow$ Enabling environment DRF IRCM existing environment

$\mathrm{DRF}$ = disaster risk financing; $\mathrm{IRCM}$ = insurance, reinsurance, and capital market.

Source: Asian Development Bank. 
market in the context of Pakistan. Nevertheless, section 4 summarizes scoring for these two areas.

\subsection{Government Policy Gaps}

37. Using the diagnostics tool, several areas where government policy could help nurture the growth of disaster insurance, reinsurance, and capital markets solutions have been identified. There is scope for strong participation by insurers, reinsurers, and the capital market in the development and implementation of a national DRF strategy. However, government policy encouraging the development of these risk-transfer instruments and removing barriers by creating the enabling environment is needed first.

\subsubsection{Household Disaster Risk Protection}

38. Scope is broad for increased uptake of disaster insurance of homes by Pakistan's rapidly expanding middle class. ${ }^{12}$ The 2005 earthquake damaged over 600,000 homes, while the 2010 floods caused total or partial damage of $\$ 1.6$ billion to more than 1.6 million housing units across the country. Figures for the 2010 floods include damage to 156,000 units of pucca housing stock, with about 65,000 completely destroyed. ${ }^{13}$ Despite this, insured losses due to the 2010 floods accounted for only about $1 \%$ of total economic losses (Swiss Re 2011). Note that separate data on property insurance is not available, but home insurance is extremely low.

39. Large corporations buying insurance include earthquake, flood, and other natural peril cover in their property insurance policies. However, given the low development of the retail insurance business (section 3.2), hardly any private house or building has disaster cover. ${ }^{14}$ The insurance sector estimates that less than $1 \%$ of the residential property in Pakistan is insured against natural hazards. This low penetration reflects the state of development of the country's non-life insurance market, its accessibility and outreach, and limited product innovation, among other factors. However, insurance affordability for families and general aversion to the concept of insurance due to credibility and lack of familiarity with the sector and religious beliefs are also key factors (World Bank 2013).

\subsubsection{Agricultural Sector Disaster Risk Protection}

40. The adverse impact of natural hazards calamities on farmers could be significantly mitigated by the use of insurance, reinsurance, and capital markets solutions. Notwithstanding the importance of Pakistan's agriculture sector for the economy of the country, very few disaster-related insurance, reinsurance, and capital markets solutions are currently available. This section proposes measures to support the development of insurance, reinsurance, and capital markets solutions to protect the livelihood of farmers and support faster post-disaster recovery hazard through readily available insurance payments.

12 Syed Mohammad Ali. 2017. Middle class Pakistan. The Express Tribune. 21 April.

${ }^{13}$ ADB and World Bank (2010) provide extensive details on these floods and their impact.

14 The exception relates to buildings or dwellings where a mortgage is involved, as banks require corresponding property insurance. 
41. The agriculture sector comprising crops, livestock, fisheries and forestry, accounts for $19.5 \%$ of GDP and employs $43 \%$ of the country's labor force (Government of Pakistan 2017a). Crops and livestock are the main contributors within the agriculture sector (Table 1). Wheat, rice, cotton, and maize are the principal crops (Table 2). For 2015-2016, rice exports, at $\$ 1.2$ billion, contributed substantially to food exports of $\$ 2.7$ billion while raw cotton production was crucial to textile exports of $\$ 9.3$ billion (Government of Pakistan 2017a). Around $90 \%$ of the area under wheat cultivation, the primary crop is in Punjab and Sindh. Sugarcane also generates significant economic activity. Smallholder farmers, those owning less than 25 acres, account for a significant share of agricultural production (Table 3).

42. Pakistan's agriculture land is divided into ten agro-ecological zones, based on classification by soil, land surface, and climate. Crops are grown in two seasons: "Kharif" (mostly rice, sugarcane, cotton and maize), with sowing from April-June and harvesting in October-November, and "Rabi" (mostly wheat, gram, and tobacco), with sowing during

Table 1: Agricultural Income in Pakistan, 2011-2012 to 2015-2016 (PRs billion)

\begin{tabular}{lcrrrr} 
& $\mathbf{2 0 1 1 - 2 0 1 2}$ & $\mathbf{2 0 1 2 - 2 0 1 3}$ & $\mathbf{2 0 1 3 - 2 0 1 4}$ & $\mathbf{2 0 1 4 - 2 0 1 5}$ & $\mathbf{2 0 1 5 - 2 0 1 6}$ \\
\hline Agricultural Sector Income & $\mathbf{4 , 7 5 3}$ & $\mathbf{5 , 3 3 5}$ & $\mathbf{5 , 9 7 6}$ & $\mathbf{6 , 5 6 3}$ & $\mathbf{7 , 0 4 1}$ \\
Crops & 1,967 & $\mathbf{2 , 1 9 3}$ & $\mathbf{2 , 6 1 3}$ & $\mathbf{2 , 7 1 4}$ & $\mathbf{2 , 6 2 5}$ \\
\hline Livestock & 2,610 & $\mathbf{2 , 9 3 3}$ & 3,130 & 3,612 & 4,146 \\
Forestry & 113 & 137 & 154 & 146 & 166 \\
Fishing & 63 & 73 & 80 & 91 & 104
\end{tabular}

Source: State Bank of Pakistan (2017a).

Table 2: Agricultural Area and Production

\begin{tabular}{|c|c|c|c|c|c|c|c|c|c|}
\hline \multirow[b]{2}{*}{ Crops } & \multicolumn{3}{|c|}{ 2013-2014 } & \multicolumn{3}{|c|}{ 2014-2015 } & \multicolumn{3}{|c|}{ 2015-2016 } \\
\hline & $\begin{array}{l}\text { Area } \\
\text { '000 ha }\end{array}$ & $\begin{array}{l}\text { Production } \\
\left({ }^{\circ} 000 t\right)\end{array}$ & $\begin{array}{l}\text { Yield } \\
(\mathrm{kg} / \mathrm{ha})\end{array}$ & $\begin{array}{c}\text { Area } \\
\text { '000 ha }\end{array}$ & $\begin{array}{l}\text { Production } \\
\left({ }^{\prime} 000 t\right)\end{array}$ & $\begin{array}{c}\text { Yield } \\
\text { (kg/ha) }\end{array}$ & $\begin{array}{l}\text { Area } \\
\text { '000 ha }\end{array}$ & $\begin{array}{l}\text { Production } \\
\left({ }^{\circ} 000 \mathrm{t}\right)\end{array}$ & $\begin{array}{c}\text { Yield } \\
(\mathrm{kg} / \mathrm{ha})\end{array}$ \\
\hline Wheat & 9,199 & 25,979 & 2,824 & 9,204 & 25,086 & 2,726 & 9,260 & 25,483 & 2,752 \\
\hline Rice & 2,789 & 6,798 & 2,437 & 2,891 & 7,003 & 2,422 & 2,740 & 6,801 & 2,482 \\
\hline Maize & 1,168 & 4,944 & 4,233 & 1,142 & 4,937 & 4,323 & 1,160 & 4,984 & 4,297 \\
\hline Cotton $^{\mathrm{a}}$ & 2,806 & 12,769 & 774 & 2,961 & 13,960 & 802 & 2,902 & 9,917 & 581 \\
\hline
\end{tabular}

ha $=$ hectare, $\mathrm{kg}=$ kilogram, $\mathrm{t}=$ ton.

a Production in '000' bales ( 1 bale $=375 \mathrm{lbs}$ or 170.09711).

Source: State Bank of Pakistan (2017a).

Table 3: Small Farm Holders, 2015-2016

\begin{tabular}{lccccc} 
& Wheat & Rice & Maize & Cotton & Sugarcane \\
\cline { 2 - 5 } & $\begin{array}{c}\text { Area } \\
\text { (Hectares) }\end{array}$ & $\begin{array}{c}\text { Area } \\
\text { (Hectares) }\end{array}$ & $\begin{array}{c}\text { Area } \\
\text { (Hectares) }\end{array}$ & $\begin{array}{c}\text { Area } \\
\text { (Hectares) }\end{array}$ & $\begin{array}{c}\text { Area } \\
\text { (Hectares) }\end{array}$ \\
\hline Total & $9,312,836$ & $3,078,586$ & 743,576 & $3,119,392$ & 986,145 \\
\% of Small Farm holders & $49.46 \%$ & $47.42 \%$ & $66.77 \%$ & $45.71 \%$ & $38.16 \%$
\end{tabular}

Source: State Bank of Pakistan (2017a). 
October-December and harvesting in April-May. The farmland is highly diverse in soil, topology, and climate, including in the Indus delta, the lower Indus plain, the southern and northern irrigated plains, the sandy deserts of the southeast and southwest, the wet mountains, and the dry western plateau (Yu et al. 2013).

43. The agricultural sector is particularly vulnerable to extreme weather events, with far-reaching negative consequences beyond physical damage. Disasters can lower production and productivity; reduce exports of agricultural commodities and increase food imports, causing disequilibrium in the balance of trade; and lower agricultural sector growth and the sustainable development of the sector (ADB 2017b, FAO 2015). In addition, production losses can directly impact manufacturing industries, such as on agro-processing, that depend on agricultural commodities and raw materials. This wider impact can derail sector growth and resonate across the national economy. For example, the 2010 floods caused damage and losses equivalent to $50.2 \%$ of total damage and losses to the agriculture livestock and fisheries sectors according to a preliminary assessment (ADB and World Bank 2010) and reduced agricultural sector growth to 1.2\% in 2010-2011 (ADB and World Bank 2014). Flood-related challenges also impacted the flow of credit to the agricultural sector, with overall credit increasing marginally by $1.4 \%$ from July 2010 through March 2011 (Government of Pakistan 2011). The fall in disbursements was largely due to a substantial $23.7 \%$ decline in lending by Zarai Taraqiati Bank (a specialized lender to the agricultural sector), which more than offset the $9.5 \%$ rise in disbursements made by commercial banks.

44. Impacts of disasters on the agricultural sector also have implications for microenterprises and small and medium-sized enterprises. The sector, accounting for a prominent $40 \%$ of GDP, is heavily dependent on agricultural production (Small and Medium Enterprises Development Authority 2016). Around 65\% of these enterprises (including about 40,000 small and cottage-sized industrial units) are in Punjab, with the agricultural sector one of their main areas of focus.

Table 4: Impact of 2005 Earthquake and 2010 and 2014 Floods on Pakistan's Agriculture

\begin{tabular}{|c|c|c|c|c|c|c|}
\hline Disaster & $\begin{array}{l}\text { Crop Area } \\
\text { Damage }\end{array}$ & Crop Losses & $\begin{array}{l}\text { Livestock } \\
\text { Losses }\end{array}$ & $\begin{array}{c}\text { Total } \\
\text { Agricultural } \\
\text { Losses }\end{array}$ & $\begin{array}{l}\% \text { of GDP } \\
\text { (actual } \\
\text { reduction) }\end{array}$ & Source \\
\hline $\begin{array}{l}2005 \\
\text { earthquake }\end{array}$ & $\begin{array}{c}\text { Not } \\
\text { quantified }\end{array}$ & $\$ 0.08$ billion & $\$ 0.25$ billion & $\$ 0.33$ billion & $0.2 \%$ & $\begin{array}{c}\text { ADB } / \\
\text { World Bank } \\
\text { (12 November 2005) }\end{array}$ \\
\hline 2010 floods & $\begin{array}{l}\text { 2,093,000 } \\
\text { hectares }\end{array}$ & $\$ 5.04$ billion & $\$ 0.57$ billion & $\$ 5.61$ billion & $2.2 \%$ & $\begin{array}{l}\text { ADB/World Bank/ } \\
\text { FAO } \\
\text { (30 October 2010) }\end{array}$ \\
\hline 2014 floods & $\begin{array}{c}\text { Not } \\
\text { quantified }\end{array}$ & $\$ 0.30$ billion & $\$ 0.05$ billion & $\$ 0.35$ billion & $0.15 \%$ & $\begin{array}{c}\text { Pakistan Economic } \\
\text { Survey 2014-2015 }\end{array}$ \\
\hline
\end{tabular}

$\mathrm{ADB}=$ Asian Development Bank, FAO = Food and Agriculture Organization of the United Nations, GDP = gross domestic product.

Sources: Durrani et al. (2005); Dorosh, Malik, and Krausova (2010); Government of Pakistan (2015). 
45. Approximately half of the lending to the farm and livestock sector is still done by informal institutions, known as Arthis. ${ }^{15}$ However, official agricultural financing recorded substantial growth in the past 5 years (Najam 2017). Disbursements increased from PRs294 billion (1.45 million borrowers) in fiscal year (FY) 2011-2012 to PRs598 billion (2.94 million borrowers) in FY 2015-2016 (State Bank of Pakistan 2017b). Average formal sector loan size is currently a healthy PRs200,000 per borrower. Diversity is observed among formal lending institutions: 52 institutions provide agricultural credit, with the top-5 commercial banks accounting for over $50 \%$ of the credit. The agricultural credit market share of the country's dedicated agricultural development finance institution, Zarai Taraqiati Bank Limited, is about $17 \%-$ a decline of about $20 \%$ over the last decade. Substantial growth in the number of formal borrowers points to greater possibility to engage borrowing farmers with agricultural insurance, ready channels for education and distribution to farmers, and use of insurance products that can provide higher client value.

46. The present agricultural insurance schemes focus on credit risk due to disaster losses incurred by the agricultural sector. The Government of Pakistan recognizes that agricultural credit is integral to the modernization of agriculture and commercialization of the rural economy. To lower the risks borrowing farmers face from natural hazards, it set up a task force under the State Bank of Pakistan to draw up an insurance scheme in 2008. The State Bank of Pakistan Task Force developed the Crop Loan Insurance Scheme (CLIS) for rice, wheat, sugarcane, cotton, and maize. Following that work, the Cabinet Committee introduced mandatory crop insurance for farm credit in July 2008 (State Bank of Pakistan 2008a), followed in 2013 with mandatory livestock loan insurance scheme for subsistence farmers (ownership below 12.5 acres) borrowing from formal credit institutions. ${ }^{16}$ The Ministry of Finance allocated PRs1.5 billion and PRs0.5 billion as premium subsidy (FY 2016-2017) to the CLIS and the livestock loan insurance scheme, respectively. The Government of Pakistan's CLIS covers formal credit to approximately 2 million of the 7 million farm sector households (State Bank of Pakistan 2015). The CLIS is underwritten by private insurers and bought by agriculture financing institutions. The State Bank of Pakistan-as the regulator of the lending institutions-is closely involved in CLIS operations. Indeed, in a March 2017 presentation, the State Bank's governor (State Bank of Pakistan 2017a) issued simplified standard operational procedures for speedy reimbursement of crop and livestock insurance claims.

47. Notwithstanding government efforts, agricultural insurance penetration remains low, with limited products and loss adjustment capacity. ${ }^{17}$ Knowledge and capacity around agricultural insurance is still limited. Product innovations are rarely seen; indeed, most insurers simply participate in the standard State Bank of Pakistan-supported CLIS and the

${ }^{15}$ Arthi is defined as the local way of referring to the businessmen who act as middlemen in the exchange of crop produce between the farmer/grower and the buyer of that crop and he often hosts the auction process at his shop in the local grain market. The term is derived from "arhat," which means commission, as the arthi takes commission for his services, usually quoted as the sale price of the crop produce and deducted up front at the time of crop sale. The arthi is already embedded in the agriculture credit market and seems to have refined his model to avoid adverse selection, control moral hazard, mitigate risk and make substantial profits in a market deemed risky and unprofitable by the commercial bankers (Haq et al 2013, page 11).

16 The subsidy is reimbursed to the credit institutions by SBP on behalf of the government.

${ }^{17}$ Insurance Association of Pakistan, 2016, Yearbook 2015-2016. Of the total FY 2015 non-life premium of PRs72 billion ( $\$ 680$ million), only about $15 \%$ is attributed to personal lines (i.e., PRs1l billion [ $\$ 100$ million]). Of this, crop and livestock insurance accounted for a mere PRs0.5 billion ( $\$ 5$ million). 
livestock loan insurance scheme that commenced in 2008 and 2013, respectively. ${ }^{18}$ Unlike South Asian peers such as India and Sri Lanka, Pakistan has no dedicated agricultural insurance underwriter. It is not seen as an attractive line of business by the existing underwriters, who run profitable commercial lines with long-term loss ratios of 50\%-60\% (Insurance Association of Pakistan 2016). The agricultural insurance business is not attractive for various reasons, in particular: (i) lack of insurers' control over underwriting outcome; (ii) relatively low share (approximately one-third) of formal agricultural credit in total agricultural credit (Haq et al. 2013); ${ }^{19}$ and (iii) low insurance cover relative to the value of agricultural outputs, as only the loan or a part of the input costs (estimated at one-fourth of the output's value) are covered. The lack of a dedicated agricultural insurance underwriter contributes to a light focus on a specialized line with its own technical requirements, such as datasets on exposures by geographic area, crop, and livestock productivity; past losses by type and severity of natural hazard; claim settlement history; and crop-specific natural catastrophe ratemaking.

48. "Pakistan Vision 2025," promulgated by the Prime Minister, includes a reduction of the food insecure population from $60 \%$ to $30 \%{ }^{20}$ Access to affordable loans is essential to achieve this. As such, agricultural insurance needs to be seen as an instrument that would increase access to loans and improve loan terms. ${ }^{21}$ For example, the availability of adequate agricultural insurance cover should reduce the cost of credit.

49. At a provincial level, activities are underway to strengthen agricultural and rural markets. The World Bank and the Government of Punjab launched a program in December 2017 titled "Strengthening Markets for Agricultural and Rural Transformation" (SMART). ${ }^{22}$ The SMART Punjab program seeks to increase the productivity of crop and livestock farmers, improve their climate resilience, and foster agribusiness. It will also improve financial sustainability and efficient use of irrigation systems and establish a crop insurance system, which could potentially leverage access to production credit. The crop insurance program aims at supporting an area yield index-based crop insurance system for subsistence farmers (as a social protection cover) and small progressive farmers, individual grower multiple-peril crop insurance for large-scale farmers; and named-peril crop insurance for farmers producing horticultural crops.

50. The SMART Punjab program aims to pilot a crop insurance scheme (Takaful) for the 2018 Kharif season in four districts-Sheikupura, Sahiwal, Loadhran, and Rahimyar Khan. This scheme will be available in its first phase for cotton and rice. In the second phase, insurance (Takaful) will be available for more crops including sugarcane, maize, wheat, orchards, and vegetables. It aims to write 1 million crop insurance policies within 5 years, gradually rolling out in other districts of the Punjab. The operational procedures

18 PRs0.5 billion (\$5 million) was allocated for the CLIS subsidy for FY 2016. Thus, nearly all the agricultural insurance premiums are generated from the government subsidized scheme. Despite 7 years of CLIS, the supply of and demand for agricultural insurance on a voluntary basis is negligible, that is, most of the industry's agricultural insurance premiums are attributed to the subsidized insurance program.

19 The agricultural financing banks and financial institutions use a standard crop insurance product offered by private sector underwriters, with premium capped at $2 \%$ of sum insured, claims based on the government's disaster notification, and claims paid to the bank to set-off the outstanding loan. According to the Agricultural Sector Strategy (Asian Development Bank 2008), informal lending institutions account for $61 \%$ of lending in the farm sector and $85 \%$ of lending in the livestock sector.

${ }^{20}$ Pakistan Vision 2025 is available at http://pc.gov.pk/web/vision.

${ }^{21}$ For more details on how insurance can help gain access to loans, see "Reference to the ADB brief on SME and Loans" at https://www.adb.org/sites/default/files/publication/298101/insurance-msmes.pdf.

22 Report no. 121616-PK, Program ID P162446. 
and regulatory framework for the crop insurance were due to be in place by April 2018. The SMART Punjab 'area yield index crop insurance scheme' will be contributory whilst building on the initial layer of the CLIS. The Government of Punjab and the farmer will share the premiums, with the expected government support for the five-year program estimated at \$379 million.

\subsubsection{Diagnostic and Recommended Actions}

51. Mandatory disaster insurance for residential property in disaster-prone areas could improve the uptake of disaster insurance for households. The low awareness among households, coupled with limited outreach of the insurance industry to provide catastrophe insurance for residential properties, and the country's significant vulnerability to natural hazards, are likely to increase the government's implicit contingent liability for rehabilitation and reconstruction of private homes in the event of disasters arising out of natural hazards. Keeping in view the low insurance and disaster risk awareness in the country, along with lesser DRM culture, a mandatory scheme would help ensure a higher level of participation and wider risk diversification, largely reducing the fixed costs and the risk of adverse selection. Government should therefore consider compulsory natural catastrophe insurance for homeowners in disaster-prone urban areas, gradually expanding to semi-rural and rural areas. ${ }^{23}$

52. Financial participation by the government as well as its active involvement in enforcing the scheme will facilitate uptake of such a mandatory scheme. To counter the perception of an additional tax and encourage people in buying disaster insurance, the government should financially support the scheme, for example by participating in the claims payments in the case of extreme events. One of the ways to do this could be providing underwriting and claims payment capacity through the state-owned insurance and reinsurance companies. The government should also consider giving incentives to the target population, such as property and income tax rebates, to stimulate the uptake of the compulsory insurance scheme. In addition, conducive measures, such as stricter enforcement of building codes, will remain important to complement the proposed insurance scheme. ${ }^{24}$ Experience has shown that even if insurance such as motor third-party liability has been made legally mandatory, enforcement of law is limited and motor third-party liability insurance remains almost nonexistent (para. 119). It will therefore remain a significant challenge for the government to ensure that once disaster risk insurance is made mandatory by law for all properties, it is implemented and adequately enforced.

53. Successful models from other countries should be carefully examined before the mandatory catastrophe insurance is introduced. Various successful models can be reviewed to design a viable scheme for the country. In France, for example, it is mandatory to have catastrophe extension to property insurance policies provided by the private sector. Policyholders are required to pay an additional cost of $12 \%$ of the property insurance premium for coverage against natural hazards. A declaration of a state of disaster by the French

${ }^{23}$ Property in rural areas is likely hurt more by natural hazards because of lower construction quality and lower enforcement of building codes. Property ownership documentation and related formalities are also more likely to be inadequate, while communities in rural and semi-rural areas typically have low purchasing power. The insurance industry is therefore likely to be reluctant to underwrite property insurance in rural areas at reasonable cost.

${ }^{24}$ Pakistan building codes are comprehensive. For more details, see Appendix 1. 
government is required before compensation is provided to claimants. Turkey provides another example, where homeowners are required to participate in a compulsory earthquake insurance scheme for private homes, the Turkish Catastrophe Insurance Pool. Purchase of policies has been incentivized by linking it to real estate purchase or sale, the contracting of utilities such as water or electricity, and by offering $20 \%$ discount at the time of annual renewal of the policy or offering substantial discounts in case of the buildings has been built after 2007, along with evidence of the existence of an insurance policy. Another successful model is the Spanish Consorcio de Compensacion de Seguros, ${ }^{25}$ which is owned by the insurance industry but managed by the government. The Consorcio covers all extraordinary risks, including disaster risk. The government provides a guarantee and a line of credit.

54. Several technical issues would need to be addressed prior to the introduction of a mandatory catastrophic insurance. A risk-profiling exercise and catastrophe modeling would have to be conducted in collaboration with the insurance industry to calculate riskbased premiums and determine the policy terms and conditions. Compulsory cover for natural hazards could be included in all fire insurance policies. In Pakistan, the collection of mandatory television fee (PTV fee ${ }^{26}$ is already linked with monthly electricity bills. A flat disaster insurance charge could similarly be included in utility bills or added as a surcharge to property tax bills. The government could start the program by covering floods or earthquakes in the first phase and gradually extend it to include other natural hazards, such as tropical cyclones, as the scheme matures.

55. Agriculture insurance has an important role to play in managing disaster risk, in particular pertaining to extreme weather events. This includes insurance at the individual farmer or micro level to smooth consumption, support continued farm activity from one season to the next, and provide income protection in the event of major weather shocks and plant disease outbreaks; at the meso level as business interruption cover to protect agriculture loan portfolios of financial institutions and input suppliers; and, finally, at the macro or government level to support the provision of disaster relief and early recovery assistance to vulnerable groups. Agricultural insurance also increases access to farm credit by reducing associated risks of lending and encourages investment in related technological tools necessary for its implementation, such as weather stations, satellite monitoring, and other weather and yield data infrastructure. An effective agricultural insurance program can additionally help farmers improve understanding of risks, incentivize risk reduction, and enhance productivity (Cai 2016). Agricultural insurance sits at the nexus of four major policy practices: (i) DRM, with regards to building disaster resilience; (ii) public finance management, in terms of addressing the impact of shocks on public finances; (iii) financial sector development, regarding its contribution to a strong financial sector; and (iv) social protection, in terms of its support for contingent financing to reach the poorest (World Bank 2014). Well-designed and executed agricultural insurance programs can rapidly deliver claims, creating incentives for investment, protecting food security, increasing farmers' resilience to weather shocks, enhancing access to credit, and reducing the cost of credit.

56. The environment surrounding agricultural insurance needs strengthening. The government is involved in the CLIS as (i) the premium payer (in the form of subsidy); (ii) the

${ }^{25}$ See the Spanish Consorcio de Compensacion de Seguros at http://www.consorseguros.es/.

${ }^{26}$ The government imposed the mandatory fee of PRs25 for domestic and PRs50 for industrial and commercial consumers in July 2004. In 2010, the mandatory fee was increased to PRs35 for domestic and PRs60 for commercial users. 
rate-maker (with premiums are capped at $2 \%$ of sum insured and are not determined on an actuarial basis); and (iii) the claim signaler (the government notifies calamities leading to claim payment in the government gazette). The system lacks sufficient checks and balances that could perhaps lead the private insurance industry to deliver greater client value. For instance, the private sector insurers can neither charge beyond the premium rate cap of $2 \%$ nor verify actual losses in collaboration with other service providers, such as loss assessors and agricultural extension personnel. The first phase of the new crop insurance (Takaful) scheme to be introduced by the Punjab government from Kharif season 2018 provides a $100 \%$ subsidy on insurance premiums for land owners with up to 5 acres of land and a $50 \%$ subsidy on insurance premiums for land owners with 5-25 acres of land. The scheme is expected to generate new learnings and spur demand for crop insurance.

57. Ordinarily, government-subsidized insurance programs also have "high transaction costs associated with asymmetric information problems (i.e., adverse selection and moral hazard) as well as other operational and administrative costs (e.g., marketing of insurance products to geographically dispersed clients, loss adjustment for yield-based insurance programs, and risk classification and monitoring systems, among others). ${ }^{27}$ Hence, evidencebased principles to justify insurance subsidies need to be established based on data collected through ongoing monitoring and evaluation. It is noteworthy that in Asia and the Pacific, the highest agricultural insurance penetration rates are in countries with large national subsidized schemes and where crop and livestock insurance is either compulsory (Japan for cereal, the People's Republic of China for livestock epidemic disease cover) or compulsory for cropcredit recipients (such as India's Pradhan Mantri Fasal Bima Yojana [FAO 2011]).

58. An agricultural insurance pool could provide underwriting capacity for increasing penetration of agriculture insurance and help establish robust links with agricultural credit providers. The constraints of agricultural insurance supply need to be overcome with a focus on major stakeholders' (insurers, reinsurers, agricultural extension services, farmer cooperatives, contract farming groups, and so on) technical capacity and policy support. As the European Commission states in the context of the European Union

even for well-developed agricultural insurance systems the coverage in terms of products and participation rates remains limited. This is true even for products which are specifically designed to provide basic safety net coverage for every farmer and which are provided at very low cost. ${ }^{28}$

As the present CLIS is neither actuarially priced nor operated on standard principles of claim assessment, the tools, infrastructure and technical capacity has not developed within the local insurance industry, weather service providers and regulator. As crop insurance necessarily relies on large volumes of risk exposure, it would be appropriate to develop greater capacity (ratemaking, climate modeling, agronomy, meteorological infrastructure, and product design skills) in rice and cotton, ${ }^{29}$ both significant contributors to agricultural sector, dependent either on minor irrigation or rain, and thus with high sensitivity to natural hazards.

27 Reyes et al. 2017. Agriculture Insurance Program: Lessons from Different Country Experiences. Discussion Paper Series No. 2017-02. Manila. page 25.

${ }^{28}$ European Commission. 2001. Risk Management Tools for EU Agriculture with a Special Focus on Insurance. Brussels. page 6.

${ }^{29}$ Rice exports at $\$ 1.2$ billion contribute substantially to food exports of $\$ 2.7$ billion while raw cotton production is crucial to textile exports of $\$ 9.3$ billion (Government of Pakistan 2017a). 
59. The government should consider establishing an agricultural insurance pool. If well designed, a pooling which commercial insurers participate could provide a series of benefits, such as risk aggregation, which in turn can create greater underwriting capacity with relatively stable premium rates. It could increase penetration of agriculture insurance and thus strengthen financial resilience among farmers:

(i) Product design: product design and provision of ongoing support is more efficient when a centralized pool gathers information and assesses insured farmers' needs. Insurance skill sets and capacity need to be developed for key agricultural crops and agro-business activities, along the entire value chain, that are exposed and are vulnerable to extreme weather events.

(ii) Information: the pool would provide a repository of crop, livestock and weatherrelated exposure and loss data for the agriculture sector, supporting in-depth analyses. For example, the data could guide decisions on ratemaking, support analysis on production and marketing decisions (including on inputs of fertilizers and equipment), inform policy on linkages with supply chain and financing, and enable decisions on risk transfer/reinsurance.

(iii) Agricultural competitiveness: improving agricultural competitiveness is increasingly necessary in integrated commodity markets. The rationale is strong for providing public support to poor households through agricultural insurance, not only on equity and efficiency grounds, but also as a tool for sustaining incomes in the aftermath of disasters and incentivizing investments.

(iv) Leverage: a pool could help ensure broader coverage and more favorable insurance terms for members, including by underwriting multiple perils, developing ratemaking capacity for selected crops and livestock products, and linking to credit institutions that lend at better terms (especially when supported by an insurance cover).

(v) Customization: a pool could offer member services, including risk control, claims management and training. For instance, the private sector and agricultural extension services could get involved in loss assessment, developing tailoring assessment methodologies for individual crops.

(vi) Innovation: a pool could support the insurance industry's development and offer unique coverage, particularly in efficient and cheap technology for indemnity and area yield index products.

(vii) Flexibility: a pool could respond to the needs of individual insurers through deductibles, varying self-insured retention levels and special coverage.

(viii) Subsidy policy: a pool could generate consolidated data useful to guide policy on premium subsidies.

(ix) Credibility: a pool could generate greater credibility than insurance products offered by individual companies by involving key public-sector stakeholders (e.g., the regulator for solvency assessment, meteorological services for data support, provincial agricultural government departments for land and yield records, and agricultural extension services for support in loss assessment).

(x) Pricing stability: a pool could offer greater pricing stability through standardized policy wording and the purchase of higher limits at a lower cost.

(xi) Control: a pool could allow greater government control of agriculture insurance, particularly if supported by a public-private partnership arrangement that plays a role in key decisions such as checks and balances on services and funding levels. 
60. The precise structure and objectives of the pool would need to be deliberated by the government and the private sector based on existing national and international experience. When designing the pool, several issues need to be addressed to ensure its success in supporting increased uptake of agricultural insurance:

(i) How should the pool be established-e.g., as an association of participating insurers or as an extended arm of the national reinsurer or as a dedicated reinsurer?

(ii) What should be its governance and legal structure, e.g., with regard to entity type, administration and board composition?

(iii) What core principles are envisaged, e.g., the frequency of communications, treatment of surplus, availability of credit lines (if the pool runs a deficit), and supervisory relationship with the insurance regulator?

(iv) How should the insurance regulator support the pool?

(v) Should the pool function as an independent underwriter that also runs its insurance business?

(vi) How should the pool enable product innovation?

(vii) What role(s) should the pool play in provision of public goods, e.g., as a data repository?

(viii) What role is envisaged for subsidy-related policy advice?

(ix) Should the pool unwind itself once private sector capacity is enhanced?

(x) Should the pool transform itself into an agricultural insurer?

61. Concerns around the definition of "agricultural index insurance" and declaration of "calamity affected area" also need to be addressed. Current insurance regulations in Pakistan do not provide a clear definition of certain agricultural insurance activities-such as index insurance-as an insurance line of business. The State Bank of Pakistan task force report on Crop Insurance in Pakistan also observed that under the National Calamities (Prevention and Relief) Act of 1958, the definition of "calamity affected area" remains vague (SBP 2008a). As the main trigger for payment of insurance claims under the CLIS depends on the declaration of a state of calamity by the government, a transparent and uniform definition of this term is needed.

62. There is also scope to improve agricultural insurance products beyond the government-subsidized CLIS and the livestock loan insurance scheme. Agricultural insurance products that incentivize risk reduction measures (e.g., better terms of coverage if farm practices reduce losses) and cropping mechanism (e.g., continued access to loans and supplemental funds to farmers after a disaster) could be developed with relevant stakeholders. Insurers could partner with the institutions involved. Institutions that enhance outcomes by supporting improved agricultural production and loss prevention practices include the Pakistan Agricultural Research Council, Pakistan Meteorological Department, and Pakistan Livestock Research Institute. Institutions engaged with agricultural financing that could help design financial products to help farmers cope after disasters include the Zarai Taraqiati Bank Limited, ${ }^{30}$ Pakistan Microfinance Investment Company, Pakistan Microfinance Network, and Sindh Enterprise Development Fund.

63. Greater advantage could also be taken of technology to enhance loss assessment and reduce operating costs associated with indemnity-based and area yield index-

\footnotetext{
${ }^{30}$ See the Zarai Taraqiati Bank http://www.ztbl.com.pk/for more information.
} 
based agriculture insurance. Index-based or parametric insurance has been implemented in several countries as the primary disaster insurance product for the agricultural sector (Fonseca 2016). In Pakistan, a parametric agriculture insurance pilot sponsored and subsidized by the Pakistan Microfinance Investment Company (formerly also known as the Pakistan Poverty Alleviation Fund) has been implemented and interest is growing among insurers and development partners in this area. However, basis risk, ${ }^{31}$ relating to the relationship between the trigger of the insurance coverage and actual losses, presents a major drawback to this type of insurance (Rao 2012). In contrast, indemnity insurance and area yield index insurance have become more practicable and affordable as newer technology has facilitated rapid damage assessments using drones and satellite imaging. With the right process design supported by technology, parametric insurance can be designed differently (e.g., area yield insurance, a combination of index and crop cutting experiments) and implemented for prompt speed of payout and lower operational cost. In terms of the process design for indemnity insurance, checks and balances (e.g., public-private partnership with policy support from the government and underwriting and loss assessment from the private sector) tend to improve when the interests of various public and private sector stakeholders are aligned. Support from development partners and weather risk service providers should be explored to enhance access to space-based technology. At the same time, domestic insurers need to engage with global insurers and reinsurers to try out innovative products.

\subsection{Credibility of Private Sector Offering Risk Transfer Solutions}

64. Insurance penetration in Pakistan has traditionally remained low. Among the 58 emerging markets, Pakistan is third last, above only Nigeria and Bangladesh at the end of 2015 (Swiss Re 2016). The combined insurance penetration has remained almost stagnant during the last 7 years. However, a closer analysis of penetration statistics reveals that the share of life insurance premiums has followed a continuously rising trend, whereas the nonlife sector, which always had a leading share of premiums, is rapidly shrinking. Interestingly, the size of life insurance premiums is now double the size of non-life premiums (Figure 5).

65. The overall credibility of the insurance industry is low. The insurance sector is generally viewed by the public with distrust because governance levels are not up to the standards. Most people in the country therefore prefer to retain their risk, as shown by low insurance penetration. The Insurance Association of Pakistan and the SECP are aware that the low credibility of the insurance industry is a key reason for low penetration. Insurance professionals have to contribute effort to create awareness and improve the overall image of insurance among the general public, the lack of which has proved a major obstacle to deepening insurance penetration. ${ }^{32}$

${ }^{31}$ Index-based insurance unlike indemnity insurance carries "basis risk." This is the risk that the losses paid by the insurance contract as read off an index are different from the losses on the ground. Basis risks can be spatial (e.g., due to its distance from the field/ grazing area, the weather station records a different weather parameter to that experienced at the field/ grazing area) and temporal (e.g., triggers are breached leading to a claim in a period different than when losses occur). This can either lead to lower customer satisfaction and affect continuity of the insurance program.

${ }^{32}$ Business Recorder. 2015. Message from Commissioner (Insurance) Securities and Exchange Commission of Pakistan. 6 May. 


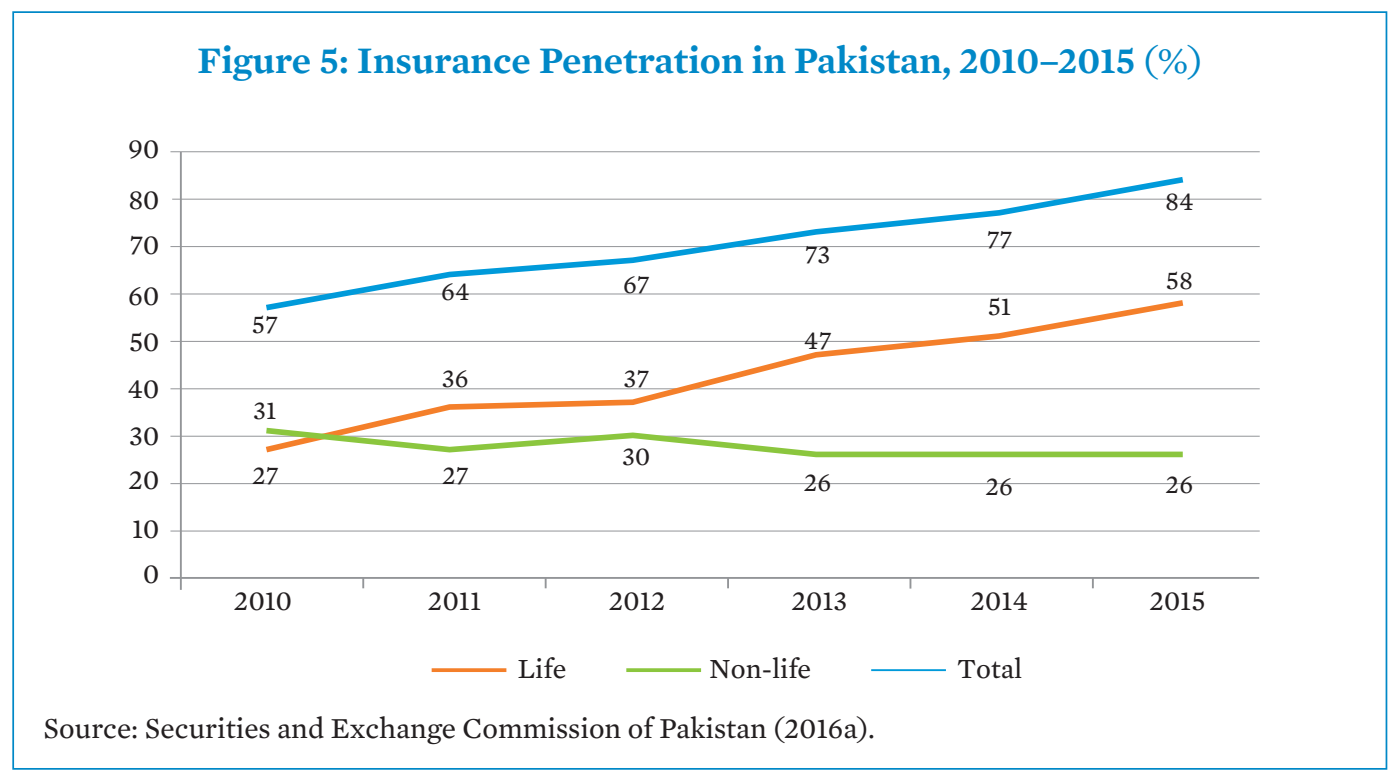

\subsubsection{Regulation and Supervision}

\section{Securities and Exchange Commission of Pakistan}

66. The SECP is the regulator of insurance and the capital market sector. As a reputable regulator, it is a member of the IAIS and IOSCO. The SECP, set up in pursuance of the Securities and Exchange Commission of Pakistan Act 1997, began operations in 1999. Since then, it has regulated and supervised the financial sector, including capital markets and the insurance industry, but excluding banks. It supervises the insurance sector under the Insurance Ordinance 2000, the primary law of insurance, under which it issues insurance regulations and through which it is responsible for licensing and supervising insurers, brokers, and insurance surveyors. The SECP supervises the securities market and exchange under the Securities Act 2015. Other relevant acts include the Companies Act 2017, the Securities and Exchange Commission Act 1997, and updated amendments, and, the Stock Exchanges (Corporatization, Demutualization and Integration) (Amendment) Act 2015.

67. Insurance supervision has evolved rapidly under the SECP. The regulator has come a long way on regulatory structure, supervisory staff, and overall regulatory purview. A 2012 assessment of the observance of the IAIS Insurance Core Principles (ICP) indicated that, of the 26 principles, two were observed and seven were largely observed. Since then, several statutes have been issued and significant amendments have been made to the regulatory framework. On 27 December 2016, a new draft insurance bill ensuring further alignment with the core principles were circulated and was sent to the Ministry of Finance for initiation of formal legislation process. SECP has conducted its own self-assessments of ICP. The most recent assessment was carried in 2017, identifying that out of 26 principles, 8 were observed, 5 were largely observed, 12 were partly observed and 1 was not observed. 
68. During 2014-2015, the SECP underwent an extensive review of Pakistan's securities regulatory and supervisory framework by the IOSCO Assessment Committee. After a detailed review of a self-assessment report and various rounds of consultation with the SECP and market stakeholders, the IOSCO Assessment Committee gave its preliminary benchmarking of Pakistan against IOSCO principles in January 2015. Since then, the SECP has implemented various reforms within its legal and regulatory framework in the light of IOSCO Assessment Committee feedback to harmonize the securities regulatory framework with international standards. Considering the reform implemented by the SECP, the assessment committee has improved the 2015 ratings assigned against various principles.

69. The 2015 IOSCO review identified the SECP's significant progress in meeting international regulatory standards and flagged areas for improvement. It found that "Pakistan has made significant improvements in the structure and practice of regulation" since the 2004 Financial Sector Assessment Program (FSAP) report. ${ }^{33}$ It also found, though, that challenges remain. The review assessed Pakistan against IOSCO principles and found it fully compliant on 13 principles, broadly compliant on 10, partially compliant on 9, and non-compliant on $5 .{ }^{34}$ The review team recommended an Action Plan to Improve Implementation of the IOSCO Principles. The SECP has since taken various measures to improve implementation of the IOSCO Principles in line with this plan.

70. Important progress has been achieved in the supervision of the capital markets since the 2015 IOSCO review. Since then, the SECP Act has amended to address regulatory gaps and amendments addressed, including changes to the composition of the policy board, SECP's role in addressing systemic risk, fast track disposal of cases, enhancement of the powers of the SECP to help address foreign regulators' requests, and the establishment of an Audit Oversight Board of Pakistan. Enhanced requirements for brokers to address the recommendations on Principles 29-32 have been incorporated into the Securities Brokers (Licensing and Operations) Regulations 2016 and the National Clearing Company of Pakistan Limited (NCCPL) successfully commenced functioning as a clearing company in May 2016. The reform also entailed "introduction of the concept of novation, transfer of risk management from the exchange to NCCPL, development of requisite operational capacity and system requirements, establishment of a consolidated settlement guarantee fund, changes to the default management procedures and major regulatory restructuring to cater for all of the above. ${ }^{35}$ However, although a number of changes to Pakistan legal and regulatory framework have been made, effective implementation of these changes is still in progress (IOSCO 2018).

\section{Consumer protection infrastructure}

71. The SECP has undertaken important initiatives to build confidence and strengthen consumer protection infrastructure. The grievance handling and alternate dispute resolution forums have been made more active and accessible to the public. A Federal Insurance Ombudsman is also available for resolution of policyholder complaints, actively

${ }^{33}$ International Organization of Securities Commissions. 2015. Country Review: Islamic Republic of Pakistan IOSCO Objectives and Principles of Securities Regulation Detailed Assessment of Implementation. Madrid. page 4.

${ }^{34}$ SECP. 2015. IOSCO Confirms SECP's Enhanced Compliance with International Securities Regulatory Standards. Press Release. https://www.secp.gov.pk/wp-content/uploads/2016/05/IOSCO-confirms-SECP\%EF\%BF\%BDsenhanced-compliance-with-international-securities-regulatory-standards.pdf.

${ }^{35}$ Associated Press of Pakistan. 2016. SECP Committed to Implement IOSCO Assessment Committee Recommendations. 13 October. http://www.app.com.pk/secp-committed-to-implement-iosco-assessmentcommittee-recommendations/. 
coordinating with the SECP. Complaints are lodged with the SECP and forwarded to relevant forums with competent jurisdiction.

\section{The following grievance handling forums exist:}

(i) Federal Insurance Ombudsman

(ii) Insurance tribunals

(iii) Small dispute resolution committees

73. The Federal Insurance Ombudsman's office is gaining momentum. The office, set up in 2010 in Karachi to provide easy access and quick relief to aggrieved policyholders, opened regional offices in Lahore and Islamabad in 2016. The Federal Ombudsman Insurance Institutional Reforms Act 2013 addressed various gaps in the existing law (Government of Pakistan, 2000) by not only ensuring the complete administrative and financial autonomy of this office, but also granting additional powers of the civil court to the Federal Insurance Ombudsman and prohibiting any other court or authority from assuming jurisdiction over matters pending with the Federal Insurance Ombudsman's office. These landmark changes, coupled with a media campaign launched by the Federal Insurance Ombudsman's office in 2016, have resulted in significant growth in the number of complaints lodged by policyholders against insurance companies, increasing $120 \%$ year-on-year in 2015. As per the Annual Report of the Insurance Ombudsman 2016-2017, the number of complaints had increased by $25 \%$ over the previous 3 years, indicating increased public confidence in the delivery mechanism and relief available to them through this mechanism. The number of complaints adjudicated and disposed of also grew, by $78 \%$, over the same period, monetary relief grew $25 \%$, and complaints amicably resolved in past 3 years rose $200 \%$ (Government of Pakistan 2017b).

74. Insurance tribunals are widespread but are overloaded with other duties. The federal government conferred powers of insurance tribunals in each province on the District and Sessions Judges in 2006, in accordance with section 121(1) of the Insurance Ordinance 2000. However, due to the heavy workload in the sessions courts, many of the SECP's complaints have been pending for the last 5 years. To provide speedy justice to the aggrieved policyholders, the SECP is now considering establishing independent and exclusive insurance tribunals, as envisaged under Sections 121, 122 and 123 of the Insurance Ordinance $2000 .{ }^{36}$

75. The SECP reconstituted existing dispute resolution committees in 2015. By amending the law, three Small Dispute Resolution Committees were reconstituted; and the pecuniary limits of claims were increased to PRs2.5 million for motor and life insurance policies and PRs5 million for domestic insurance policies. Each committee consists of three members: a chartered accountant or a management accountant, a lawyer, and a professional representative of the Insurance Association of Pakistan. The decisions of these committees are binding on insurance companies.

\subsubsection{Insurance Providers}

76. There are $\mathbf{5 0}$ insurance companies in Pakistan, including 9 life insurers, 40 nonlife insurers, and 1 state-owned national reinsurer. Fourteen entities have obtained broker licenses. In 2015 , the sector grew by $17 \%$ and the total premium of the non-life insurance

\footnotetext{
${ }^{36}$ The Express Tribune. 2015. Special courts: SECP Suggests setting up insurance tribunal. 23 January.
} 
sector reached PRs71.34 billion (SECP 2016a), excluding reinsurance. The SECP also allowed five non-life insurers to transact window takaful business during the year, through which conventional insurers were able to underwrite takaful products. There are nine life insurers, including two family takaful operators, and one state-owned insurer in the life insurance sector. The life insurance market grew by $24 \%$ in 2015 , with total premium standing at PRs161.94 billion. The insurance market in is fairly liberalized as 100\% foreign ownership and control of insurance companies is permitted, though there are only two locally incorporated foreign insurers in the country.

77. The government has a significant presence in the insurance sector and owns two insurances and one reinsurance entity. Three of these public-sector insurers fall under the administrative control of the Ministry of Commerce: State Life Insurance Corporation (SLIC), National Insurance Company Limited (NICL), and Pakistan Reinsurance Company Limited (PRCL). Postal Life Insurance falls under the administrative control of the Ministry of Finance. However, the enforcement capability of the regulator over these entities remains diluted because of ownership-structure-related conflicts of interest and major governance failures have affected the NICL and the PRCL.

\section{State Life Insurance Corporation}

78. The State Life Insurance Corporation holds the dominant position in the life insurance sector. The life insurance business in Pakistan was nationalized in March 1972. In November 1972, 32 life insurance companies were consolidated and merged into SLIC. The life insurance industry remained a virtual monopoly of SLIC until 1992, when the private sector was allowed to enter the insurance business again. SLIC still holds a dominant, albeit declining, position in the market. It is the largest public-sector insurer, with over 5,000 employees, 200,000 agents, and 5.5 million customers; has a strong brand and good will; has significant resources, including assets over PRs600 billion; and enjoys a sovereign guarantee. SLIC has always been profitable. Its after-tax profit for 2015 totaled PRs1.05 billion. Some $64 \%$ of its business is generated from rural areas, where the private sector has not yet penetrated. It distributes $97.5 \%$ of its surplus to policyholders annually, more than the $90 \%$ statutory requirement. The corporation's individual life first year premium was PRs17.1 billion in 2016.

79. SLIC enjoys the advantage of being the insurer of first choice for the publicsector life and pension schemes and thus requires strong governance. As the largest life and health insurance provider in the country with a huge outreach in the remotest rural and urban areas, SLIC can be leveraged to sell disaster insurance products to protect life and disability of individuals. This position has been acknowledged by the government, for example, by assigning the recently started prime minister's national health insurance program exclusively to SLIC. The Prime Minister's National Health Insurance Program is a milestone towards social welfare. State life, in collaboration with the Ministry of National Health Services, Regulation and Coordination aims to cover 26 districts (including Islamabad, Muzaffarabad and Quetta) of Pakistan containing almost 2 million families below the poverty line. The coverage includes secondary care of PRs50,000 and priority treatment care of PRs250,000 per family per annum. The scheme is expected to massively impact the quality of health care available to the poor. However, that SLIC's has lost 26 percentage points of its life insurance market to its competitors during $2006-2015$, from $75 \%$ to $49 \%,{ }^{37}$ raises questions about its ability to capitalize on the advantages of its dominant position.

${ }^{37}$ Annual Accounts of SLIC from 2006-2015. 
80. SLIC, in collaboration with the Government of Khyber Pakhtunkhwa, has launched Social Health Protection. This scheme will provide and promote social and micro health insurance scheme for the deprived population in 24 districts of Khyber Pakhtunkhwa. The scheme targets the most deprived segment of society and provides them access to health facilities in a wide range of public and private hospitals. Members will be covered for hospitalization, day care surgeries and maternity benefits up to PRs25,000 per person per annum. Just over 1.4 million families had enrolled in the scheme as of early 2018.

81. Important initiatives are under way to strengthen SLIC. A conditionality under the World Bank's $\$ 800$ million Development Policy Credit (PDC-III), which is intended to increase growth and competitiveness in the financial sector, is to convert SLIC from a corporation into a company, to improve its performance and governance. The government is already committed under its International Monetary Fund program to list SLIC on the Pakistan Stock Exchange (PSX) and make an initial public offer of up to 15\% shares. While it is perceived that the social responsibilities of SLIC as a corporate body may be undermined by these changes, its corporatization and privatization will certainly improve its risk management and governance structure.

\section{National Insurance Company Limited}

82. The National Insurance Company Limited was incorporated in 2000 as an unquoted public limited company and has a paid-up capital of PRs2 billion. Fully owned by the government, NICL was set up with the primary objectives of insuring public properties, advising the government on risk management, and building sufficient reserves to increase risk retention capacity. ${ }^{38}$ As per Section 66 of the 2000 Insurance Ordinance, NICL has an exclusive mandate to insure all public property. ${ }^{39}$ Its share of $12 \%$ in the country's total nonlife insurance premium has been sustained over the past few years. However, despite its exclusive mandate to insure public assets and the country's increasing vulnerability to natural hazards, NICL offers natural catastrophe insurance under the "Atmospheric Disturbance" cover as an endorsement to the Standard Fire Policy to all its policyholders. Apparently, however, it does not have any specific insurance program for the protection of national assets against natural hazards. Even critical life-line government infrastructure crucial for postdisaster relief, rescue, and reconstruction remains uninsured. As a result, the company has consistently maintained abnormally low loss ratios, ranging around $20 \%$ against the market average of $60 \%-65 \%$, even in the 2010 Indus floods, one of the most devastating, with total economic losses of $\$ 10.5$ billion (World Bank 2013).

83. NICL should be strengthened to provide disaster insurance cover for public property. A detailed assessment of the reserve adequacy, asset quality, and risk management of NICL, including its reinsurance arrangements should be carried out to determine its capacity to provide cover against natural hazards. Once resulting recommendations have been implemented, an effort should be made to increase disaster insurance cover of public property. This effort should begin with the development of an inventory of government property and an assessment of its exposure and vulnerability to natural hazards and other severe events, forming part of the assessment of sovereign contingent liability and hence to the identification of appropriate insurance programs and other DRF instruments.

\footnotetext{
${ }^{38}$ National Insurance Company Limited. http://www.nicl.com.pk/about-nicl.aspx.

${ }^{39}$ Insurance Ordinance 2000, section 66, promulgated by the President of Pakistan after repealing the Insurance Act 1938.
} 


\section{Postal Life Insurance}

84. The British Raj established Postal Life Insurance in $\mathbf{1 8 8 4}$ to insure the lives of mail runners. After the independence of Pakistan, it started offering life insurance to the general public. It is exempt from corporate and income taxes. All the income generated is invested in the Post Office Insurance Fund, which is controlled by the Ministry of Finance. Pakistan Post gets a return at the prevailing government investment return rates. Postal Life Insurance has an extensive network of post offices in the far-flung areas of the country which serve as its sales outlets. This enormous advantage could be leveraged to increase life insurance penetration in the rural areas, where the private sector has limited outreach, and thus enable the government to achieve its goals under its National Financial Inclusion Strategy and other development goals. To increase Postal Life Insurance's underwriting capacity, public-private partnerships might be useful.

85. Postal Life Insurance is a large social safety welfare provider but is exempt from the SECP's regulatory oversight. Postal Life Insurance extends significant support to the government in providing microinsurance products such as life, disability benefits, and accidental injuries protection. However, Postal Life Insurance is not registered with the SECP and does not fall under its regulatory oversight. ${ }^{40}$ There are plans to corporatize and supervise Postal Life Insurance ${ }^{41}$ which, if implemented, will help enable effective monitoring of its resilience, safeguard the interest of its low-income policyholders, and create a level playing field should private insurers be interested in entering this market segment.

\section{Pakistan Reinsurance Company Limited}

86. Pakistan Reinsurance Company Limited (PRCL) was established in 1952 as a reinsurance corporation under Pakistan Insurance Corporation Act to support the local insurance industry. It is majority owned by the government and has shares listed on the stock exchange. It was converted into a public limited company in 2000. Seven of its nine directors are nominated by the government. Its vision is to "be a leading provider of re-insurance and risk management services in the region." ${ }^{42}$ All insurance companies are mandated to offer $35 \%$ of their re-insurance treaty business to PRCL, which has the first right of refusal. An important source of business comes from these mandatory cessions. PRCL has had experience of managing the National Insurance Fund, National Coinsurance Scheme, War Risks Insurance, and Export Credit Guarantee Scheme in the past. However, it has no regional presence beyond the management of the Economic Co-operation Organization Pool between Iran, Pakistan, and Turkey. ${ }^{43}$

\subsubsection{Insurance Support Services}

87. A well-functioning insurance sector requires the establishment and availability of insurance support providers. Actuaries should be available to calculate premiums and

${ }^{40}$ Postal Life Insurance was accorded exemptions under the repealed Insurance Act 1938 and the Life Insurance (Nationalization) Order 1972, (the Order). However, it is unclear if such exemption exists anymore following the promulgation of Insurance Ordinance 2000 and the Pakistan Postal Services Management Board Ordinance 2002.

${ }^{41}$ This is being done with the assistance of World Bank, as disclosed by the Postal Life Insurance management during the mission meetings in May 2017.

42 Pakistan Reinsurance Company Limited. http://www.pakre.org.pk/ms/Business-Overview.html.

${ }^{43}$ The Economic Co-operation Organization Pool was set up in 1964 aimed at bringing the economies of these countries together and increasing retention capacity for non-life business. 
liabilities of insurers, in particular for the more complex products and long-term business. Accounting and auditing functions with sufficient expertise in insurance are of relevance to support transparency of the operations and early identification of issues that could manifest in the future. Rating agencies are central to support the supervisor in enhancing market discipline. Data providers, particularly for the product design of index insurance and for pricing of standard products, are also necessary.

88. Pakistan achieved good marks in an assessment of accounting and auditing finalized in January 2017 under the Report on the Observance of Standards and Codes Initiative of World Bank (World Bank 2017b). According to the assessment, Pakistan is fully compliant with the International Standards of Auditing and has adopted most of them. It also states that the International Financial Reporting Standards are adopted; however, full compliance cannot be claimed because of a small number of exemptions and deferrals, mainly in the banking sector. The country has a good number of qualified accountants who continue to play an important role in strengthening the regulatory framework by working with key policymaking institutions, including State Bank of Pakistan, the SECP, the Federal Board of Revenue, and other government entities. Currently, more than 7,000 members are registered with the Institute of Chartered Accountants Pakistan.

89. The insurance sector is sufficiently supported by two local credit rating agencies. The SECP formulated the Credit Rating Companies Rules, 1995, as a first step in introducing and recognizing the importance of credit ratings in Pakistan. A new regulatory framework, the Credit Rating Companies Regulations, was introduced in 2016 to reflect the changing environment. Currently, two companies are licensed as Credit Rating Companies: JCRVIS Credit Rating Company and the Pakistan Credit Rating Company. The majority of the insurance companies get themselves rated by these two agencies. However, some large companies are now also being rated by an international rating agency, A.M Best. In May 2011, another international rating agency, Islamic International Rating Agency entered into a formal technical affiliation agreement with two of its rating agency shareholders, providing a platform for the agency to collaborate with JCR-VIS Credit Rating.

90. The insurance sector would benefit from more actuaries and surveying companies. Currently Pakistan has around 40 qualified and 70 student actuaries. Most work as pension consultants or are employed by the life insurance companies, banks, investment companies, the SECP, and the Ministry of Finance. The actuaries working for life insurance companies support risk management and evaluation of new life insurance products. The nonlife sector uses the actuaries mainly for health insurance schemes. The uncovered demand for actuaries is satisfied by foreign actuaries. A total of 604 insurance surveying companies and surveying officers were licensed by the SECP in the year 2015 that could be deployed by the insurance companies to verify and evaluate disaster claims. Once insurance penetration increases, the demand for surveyors, especially in the event of a major disaster, will not be satisfied. Solutions such as pre-agreements with foreign providers should therefore be considered.

\section{Meteorological services}

91. The Pakistan Department of Meteorology's mainly provides information on weather, climate, and geophysical phenomena to help mitigate disasters, improve safety, develop agriculture based on climatic potential, address climate change, assess impacts, 
and project climate and adaptation options. ${ }^{44}$ In its range of services, some are greatly relevant to the insurance sector, including agro-meteorological services, flood forecasting, geophysical and seismological services, and hazard early warnings. The department employs 2,400 people across about 60 locations. Its direct public services include weekly forecasts and monthly bulletins, fortnightly drought bulletins based on satellite data, and short- and medium-range forecasts.

92. Notwithstanding important developments in the Department of Meteorology capacity, data availability remains insufficient for development of index insurance. The department has divided the country into 12 agro-climatic zones, but only 50 automatic weather stations are available, of which 18 are in Punjab, home to about three-quarters of Pakistan's agricultural output. The department has five agro-meteorological centers, two each in Balochistan and the Punjab and one in Sindh. It maintains data on temperature, humidity, precipitation, evapotranspiration, and wind speed. During the consultation mission, the Department of Meteorology was receptive to sharing its weather data (50 years of daily data available), and statistical models with development partners. The department's knowledge of weather and climate patterns across Pakistan's geographies would be extremely useful to the development of actuarially priced agricultural and other insurance products. It could also improve understanding of natural hazards for decisions on DRF and disaster risk reduction. Greater coordination between the insurance industry and the Department of Meteorology is needed to provide a strong basis for pricing and designing agricultural insurance products and build capacity in data analyses and weather forecasting.

\subsubsection{Microinsurance}

93. Significant buzz has surrounded the microinsurance sector in Pakistan in recent years amid vibrant indicators and market potential. The SECP's significant and continuous efforts have made this possible, as well as the actions of a handful of insurers engaged in microinsurance, and public-sector organizations seeking to increase access. Engagement is also increasing with the donor community, international development organizations, and public stakeholders.

94. Until 2010, microinsurance products in Pakistan were mainly credit life insurance for microfinance borrowers. ${ }^{45}$ However, in 2010, as the SECP became aware of this important insurance industry segment and the overall agenda of financial inclusion, momentum picked up. The World Bank FIRST Initiative gave the SECP technical assistance to undertake the first-ever diagnostics assessment of the state of microinsurance in Pakistan, assessing demand and supply gaps, regulatory intervention needs, and the plausibility of a microinsurance regulatory framework. The SECP's microinsurance diagnostic study of October 2012 found that people would like insurance, in descending order, for health/illness, disasters triggered by natural hazards, marriage, education, death, business loss, childbirth, and accidents (SECP and World Bank 2012). The initiative culminated in the issue of a dedicated regulatory framework for microinsurance in Pakistan in early 2014, known as the SEC (Microinsurance) Regulations, 2014.

${ }^{44}$ The Pakistan Meteorological Department's objectives can be viewed at http://www.pmd.gov.pk/PMD/pmdinfo. html.

45 This report uses microinsurance provider both for microfinance banks and microfinance institutions. Both provide microfinance services. However, microfinance banks are licensed and regulated by the State Bank of Pakistan as banking companies, while microfinance institutions operate in a nongovernmental organization structure. 
95. Several insurance companies, life and non-life, are offering microinsurance products. Preferred channels of provision include through microfinance providers, branchless banking channels, and telecom companies, and a variety of business models. Although no special license now exists for exclusive microinsurance companies, the SECP remains committed to the development of a microinsurance segment and is open to a tiered-approach. It is considering the introduction of lower capital requirements and the relaxation of solvency requirements, as appropriate to the risks assumed for dedicated microinsurance companies. To encourage investments in microinsurance infrastructure, the commission is also considering products covering life and non-life at the same time. And to promote the benefits of insurance among the low-income population and encourage insurers to cater to this market, it is also considering minimum quotas for the microinsurance business, in addition to carrying out better monitoring and reporting of social microinsurance schemes (SECP 2015).

96. However, insurance companies have had limited success and less interest in targeting low-income households. The share of microinsurance premium in the industry's overall gross written premium remains in single digits. Based on international experience, for successful uptake of microinsurance, the involvement of conventional insurance players needs to be complemented by other stakeholders such as donors and development institutions. Microfinance providers and microfinance sector representatives such as the Pakistan Microfinance Investment Company and the Pakistan Microfinance Network need to be involved; branchless banking operators are required to act as distribution channels; technology providers are required to serve as or facilitate third-party administrators; training providers and capacity development institutions are needed; and specialized agencies, including government-line departments and the Metrological Department among others, are required to provide the input data critical for the success of microinsurance initiatives.

97. Microinsurance regulation is required to support insurance access for the lowincome population. ${ }^{46}$ The SEC (Microinsurance) Rules 2014 were expected to stimulate microinsurance business, but the resulting growth has been nominal. ${ }^{47}$ Insurers shy away because of the following:

(i) the sector's small transaction size;

(ii) insurers' lesser rural and semi-urban outreach;

(iii) challenges in commercial viability of microinsurance due to dependence on subsidies;

(iv) administrative cost in developing delivery channels, requiring significant capital but with low returns in the initial stages;

(v) major technological investment requirements;

(vi) lack of understanding about the microinsurance market segment, which requires a different strategy and business model and multiple partnerships between diverse stakeholders; and

(vii) lack of reliable information about market needs and associated risks.

98. Given the country's high disaster risk, the development and provision of appropriate disaster risk reduction measures for low-income households is also extremely important. Such measures, like enforcement of building codes, retrofitting of rented

\footnotetext{
${ }^{46}$ Microinsurers should then be required to get appropriate reinsurance to withstand disaster or major event.
}

${ }^{47}$ Based on discussions with the Insurance Association of Pakistan. 
buildings, prohibition of construction in known flood or landslide zones, are particularly important as this population is especially vulnerable to natural hazards and has limited resources for dealing with disaster.

\subsubsection{Capital Markets}

99. The SECP is supported by several self-regulatory organizations in the supervision of the capital markets. As the SECP stated,

the Securities and Exchange Commission of Pakistan (SECP) as the apex regulator of the Pakistani capital markets is entrusted with the overall development and regulation of the capital market, the Self-Regulatory Organizations (SROs) and the intermediaries operating in the capital market, and protection of investors. The SROs include the Pakistan Stock Exchange (PSX), the National Clearing Company of Pakistan (NCCPL), the Central Depository Company of Pakistan Limited (CDC), and the Pakistan Mercantile Exchange Limited (PMEX). The various intermediaries in the capital market include securities advisers, brokers and managers, debt securities trustees, balloters and share registrars, credit rating companies, and underwriters. ${ }^{48}$

100. The PSX, inaugurated in January 2016, is the only stock exchange in Pakistan after merger of the Karachi, Lahore, and Islamabad Stock Exchanges. As of June that year, it listed 559 companies with a market capitalization of PRs7,677 billion ( $\$ 73.32$ billion). Market capitalization increased by $283.7 \%$ from 31 December 2012 to 16 June 2016 and average daily turnover of 185.15 million shares in the ready market and 37.55 million shares in the futures market over January-June 16, 2016. As of end-June 2017, there were 560 companies listed on PSX with listed capital of PRs1,317 billion. Market capitalization reached PRs9,522 billion, corresponding to 30\% of GDP. Trading volumes of PRs 236 million were registered, implying a 104\% year-on-year increase, with trading value of PRs9,393 million. In 2016, Bloomberg ranked the PSX (KSE-100 Index) the fifth best performing stock market in the world. The KSE 100 Index grew 23\% between 30 June 2016 and 30 June 2017, while the KSE 30 Index grew around $12 \%$.

101. The Pakistan Mercantile Exchange Limited is the country's first and only demutualized commodity futures exchange, operating since 2007. It is regulated by the SECP and provides a platform for trading; clearing and settlement; custody; and back office services for futures contracts in commodities. The exchange joined the Association of Futures Markets as an Associate Member in March 2012 and was granted a full membership in February 2014. The Pakistan Mercantile Exchange also joined the Futures Industry Association in 2014 and has signed collaboration agreements with the exchanges in Dubai, Iran, and Turkey.

102. As SECP stated

Custody and depository services are provided by the CDC which handles the electronic settlement of transactions at the stock exchange. The CDC also provides trustee and custodial services for the mutual fund industry and share registrar services for the

\footnotetext{
${ }^{48}$ SECP. 2016. Capital Market Development Plan (2016-2018). Islamabad. page 6.
} 
corporate sector. The clearing and settlement function is centralized at the NCCPL which provides for integrated settlement of trades executed at the stock exchange in dematerialized shares. The company also provides an institutional delivery system facilitating direct settlement of institutional trades, margin financing and margin trading modules and registration of Unique Identification Numbers (UINs). Additionally, NCCPL is responsible for computing, determining, collecting, and depositing Capital Gains Tax (CGT) to the national exchequer on behalf of the capital market investors. ${ }^{49}$

\subsubsection{Diagnostic and Recommended Actions}

103. Several actions are required to enhance credibility in the insurance sector and the capital markets. These include advancing observance of international regulatory and supervisory standards as set by the IAIS and IOSCO; increasing the resilience of PRCL and NICL, which are important in maintaining the solvency of the insurance sector and insuring public assets; and raising insurance awareness by developing personal lines of disaster risk insurance, including disaster risk microinsurance.

104. Regulation and supervision of the insurance and capital markets in Pakistan has made significant progress, but scope for improvement remains. Overall, the legal and regulatory environment for insurance is well-structured and well elaborated. However, room remains for modernization to achieve full observance of IAIS and IOSCO principles and standards. A higher level of observance of these principles would create more resilient financial sectors; help identify any capacity development needs for SECP staff; enhance the sufficiency of market conduct factors; and attract foreign participants to the market with new products, technology, and capital.

105. The SECP's efforts to observe international regulatory and supervisory standards could be properly acknowledged by carrying out an independent assessment. The SECP has implemented a new insurance law and significantly amended the SECP Act and securities related regulations that address several of the IAIS and IOSCO principles, helping raise the observance of these principles. The SECP should undergo full Insurance Core Principles and IOSCO assessments to get full credit for its efforts and to identify and develop plans to close gaps for greater compliance with IAIS and IOSCO principles.

106. PRCL's resilience is critical for the solvency of the insurance sector as it reinsures at least $35 \%$ of the insurance market. As per prevailing law, non-life insurance companies are required to offer a minimum of a $35 \%$ share ${ }^{50}$ of all reinsurance treaty business to PRCL, which has first right of refusal. This implies a significant concentration of disaster risk in the company. PRCL has no risk models to quantify its exposure to disasters, and hence relies heavily on the advice of its international reinsurance brokers to determine the level of retrocession required to protect its reinsurance portfolio. It is recommended that PRCL, under the close supervision of the SECP, assess in detail its reserve adequacy, asset quality, ${ }^{51}$ retrocession agreements, and risk management, including stress testing to evaluate PRCL's resilience in case of major disaster, which could become more frequent due to climate change.

\footnotetext{
${ }^{49}$ Footnote 48. page 8.

${ }^{50}$ Pakistan Reinsurance Company Limited. http://www.pakre.org.pk/ms/Business-Overview.html.

${ }^{51}$ As prescribed by SECP in Section 12 of the Insurance Rules, 2017.
} 
107. As the designated insurer for public assets, NICL needs strong risk management. To ensure the proper level of protection of public-sector property, particularly in major disasters, ${ }^{52}$ NICL should assess in detail the reserve adequacy, asset quality, ${ }^{53}$ reinsurance agreements, and risk management, including stress testing against major disaster, under the close supervision of the SECP. It should then address any deficiencies. Once adjustments have been made, effort should be undertaken to increase disaster insurance coverage of public-sector property through NICL, with special focus on lifeline infrastructure, which is crucial for disaster relief, early recovery, and reconstruction operations.

108. Customized insurance awareness programs for disaster insurance should continue to be developed. One of the challenges in expanding the market for disaster insurance, especially among Pakistan's low-income people, is the country's low overall literacy and education, ${ }^{54}$ which inhibit understanding of possible DRF options. Improving overall financial literacy could increase insurance understanding and awareness. Awarenessraising programs are required, tailored to local needs, religion, and culture in different parts of the country, including components on disaster insurance, claims process, and complaints resolution and Sharia compliant insurance. Use of Federal Insurance fees could finance this customized insurance awareness program. ${ }^{55}$ The SECP has already launched an investor education initiative, JamaPunji, to increase financial literacy. Microfinance providers have also been important in advancing insurance awareness. However, the SECP and the Insurance Association of Pakistan have not yet developed a specific program on insurance. ${ }^{56}$

109. Successful implementation of crop insurance requires high investment in yield and weather-data repositories, risk modeling, technology, distribution, and lossassessment techniques. The highly volatile climate, diversity of farmland conditions and agricultural output, varied incidence of natural hazards, and seasonal agriculture require a greater focus on crops that contribute to the agricultural output and food security of Pakistan. Stakeholders such as Pakistan Agricultural Research Council, National Agricultural Research

52 The chairman of NICL said that only $30 \%$ of public assets are insured and that only during the construction phase.

${ }^{53}$ As prescribed by the SECP in Section 12 of the Insurance Rules, 2017.

54 The overall literacy rate stands around $57 \%$ in Pakistan with $73 \%$ in urban areas and $49 \%$ rural areas. Less than $10 \%$ of people have been enrolled in high school or received a college/university level education (Government of Pakistan 2017a).

55 The industry has been collecting and depositing a federal insurance fee of $1 \%$ of the premium received on insurance policies. The fee was levied by the Government of Pakistan in the 1989-1990 budget. Since then, about PRs3.5 billion on account of the federal insurance fee has been collected and handed over to the Ministry of Finance. This amount, coupled with the Annual Supervision Fee of $0.02 \%$ of the gross written premium by insurers annually, subject to a maximum of PRs50 million per insurer, is also collected by SECP; this funding, with the unclaimed benefits/dividends of life policyholders, should generate adequate funds for a comprehensive insurance awareness program and to develop the insurance market. See the SECP's website https://www.secp.gov. $\mathrm{pk} /$ document/circular-no-20-annual-supervision-fee-for-the-year-.

56 The SECP has established "JamaPunji" an investor education initiative to raise financial literacy in Pakistan. Digital activities include the use of the JamaPunji portal to disseminate investor education material and offers educational videos and a mock trading simulator for hands-on experience of stock trading. JamaPunji also organizes seminars, webinars, radio programs etc. for students, professionals and the general public. The SECP has signed 33 MoUs with academic institutions in the context of promoting financial literacy as well. The program aimed at promoting financial literacy and awareness for the regulated sectors of the SECP including capital markets, insurance, nonbanking finance companies, corporate sector and Islamic finance. The investor education and international relations department (IEIRD) at the SECP has executed various awareness sessions on insurance, developed guidebook titled "Insurance Basics" explaining the basics of insurance for the general public. Further, IEIRD is also currently working on developing specific awareness programs on various concepts of insurance including the free look period, comparison between conventional insurance and takaful, measures available for investors to address grievances and complaints to name a few. 
Council and provincial departments of agriculture see rice and $\operatorname{cotton}^{57}$ (Table 2) as important crops around which agricultural insurance skill sets and capacity should be developed, at least initially and with the possibility of underwriting large risk exposures. Rice and cotton (unlike wheat in Punjab) are particularly vulnerable as they are grown in rain-fed or partly irrigated farms and are therefore more exposed to extreme weather events.

110. Although the SECP promulgated the microinsurance regulatory framework relatively recently, in 2014, there is a clear need for revisiting the microinsurance regulatory framework to identify weaknesses and challenges. These emanate mainly from provisions relating to insurers' voluntary adoption of microinsurance rules, whereby they are free to decide to label an insurance product as a microinsurance product, and thus follow the rules. In most cases, insurers have classified the products as non-microinsurance products, avoiding the applicability of the rules altogether. However, within the insurance industry's domain, there has been recent recognition of microinsurance as a separate business proposition, and some insurers have started to offer formally approved microinsurance products, with the SECP approving the first microinsurance product in $2016 .^{58}$ There is also no separate regulatory reporting of microinsurance business, and, thus, noquantitative information about this important business category available with the regulator, such as product details, the number of policyholders, claims records, and so on. This does not imply that microinsurance is limited or nonexistent. Rather, most microinsurance products are offered without regulatory approval. As such, the 2014 microinsurance regulatory framework needs to be revisited to identify weaknesses and challenges that might preclude the classification of products as microinsurance. This is important for the development of disaster-risk microinsurance products. Without the observance of robust microinsurance rules for consumer protection and codes of conduct for microinsurance agents, it is possible that the target low-income population will remain exposed to risks of customer abuse and malpractice. It should be noted that there are plans to address these needs, with a separate chapter on microinsurance included in the 2017 draft insurance bill sent to the Ministry of Finance for initiation of formal legislation process.

\subsection{Product Availability and Affordability}

\subsubsection{Insurance Products}

111. A wide range of traditional insurance products are available for corporates, while the retail market remains largely untapped. The insurance sector has been focusing on corporate business and offers a wide range of traditional products (Box 3). In contrast, with an overall insurance penetration of $0.84 \%$ in 2016 , of which $0.58 \%$ was life and $0.26 \%$ was non-life insurance, the personal lines business in non-life insurance is relatively small. This is due to a variety of reasons, including low income levels, limited financial/insurance

${ }^{57}$ Rice exports accounted for $\$ 1.2$ billion of food exports totaling $\$ 2.7$ billion from July 2016 to March 2017. Raw cotton is essential for textile manufacture exports totaling $\$ 9.3$ billion over the same period (Government of Pakistan 2017a).

${ }^{58}$ Pakistan Observer. 2016. SECP Approves First Sehat Tahafuz Plan microinsurance product. 3 May. http:// pakobserver.net/secp-approves-first-sehat-tahafuz-plan-microinsurance-product/; The News. 2016. "SECP Approves New Product. 3 May. https://www.thenews.com.pk/print/116956-SECP-approves-new-product; and Dawn. 2016. SECP Approves Micro-Insurance Product for Low-Income Group. 3 May. https://www.dawn.com/ news/1255852. 


\section{Box 3: Traditional Insurance Products Available in the Market}

Property: Fire (Dwellings, Commercial and Tea Factories), Combined package insurance such as hotelier's, shops, homes and offices, business interruption, contractor's all risks, erection all risks, machinery breakdown, machinery all risks, boiler explosion, contractor's plant and machinery, electronic all risks, business interruption insurances connected with engineering insurance, advance loss of profit insurance, deterioration of goods in cold storage, burglary, fire and theft for dwellings plate glass and neon signs.

Marine: import and export insurance, stock throughput insurance, import/export open covers, goods in transit, freight forwarder's insurance, marine hull and machinery, fishing boats and pleasure crafts.

Motor: comprehensive covers, third party fire and theft and third-party liability only for private cars, commercial vehicles, motorcycles, three wheelers, special types vehicles and trade plate insurance for garages and motor vehicle dealers.

Liability: public liability, professional liability, products liability, product recall, workmen's compensation/employer's liability and director's and officer's liability.

Miscellaneous: personal accident, surgical and hospital expenses, travel insurance, fidelity guarantee, banker's indemnity/banker's blanket bond, cash in transit, all risks insurance, aircraft insurance, title insurance and surety bonds (bid, performance, advance payment and retention).

Prevalent life insurance products are the unit linked type of products offered by the private sector and traditional endowment products offered by State Life Insurance Corporation.

Source: Discussion with the Insurance Association of Pakistan.

literacy and awareness, religious factors, and limited outreach of insurers as the distribution channels to service the population in semi-urban and rural areas remain underdeveloped.

112. Globally, the personal and commercial lines split has been about 50/50 for many years (Insurance Information Institute 2015). However, in Pakistan commercial lines of business account for almost $85 \%$ of the premium and personal lines for only $15 \% .{ }^{59}$ Although property and casualty retail products are available, such as homeowner's insurance, flood and earthquake insurance, life and disability, and health insurance, the industry has focused on commercial insurance.

113. The non-life insurance sector has been growing slowly, with property insurance remaining the largest portfolio. Property insurance generated gross written premiums of PRs21.3 billion in 2013, PRs22.6 billion in 2014 and PRs23.4 billion in 2015, showing a combined

\footnotetext{
59 This is an industry estimate, as accurate data is not available from the SECP or the Insurance Association of
} Pakistan. 
average growth ratio of $3.18 \% \cdot{ }^{60,61}$ Commercial lines account for a major share of this business, comprising the industrial, manufacturing, oil and gas, banking, and multinational sectors. ${ }^{62}$ Individual motor insurance is the major contributor to growth in personal lines, mainly due to the high incidence of car thefts and rapid growth of car leasing. Overall auto insurance premiums totaled PRs10.3 billion in 2013, PRs11.7 billion in 2014, and PRs13.5 billion in 2015, implying a combined average growth ratio of 9.55\% (Insurance Association of Pakistan 2017). Premium of PRs5.5 billion was written for personal accident and health cover in 2015.

114. Natural peril cover is provided as add-ons to the Standard Fire Policy under the allied peril of "Atmospheric Disturbance," rather than as separate cover. No actuarial or technical methodology is used to price disaster risk. Rather, the market follows the rates of the reinsurers.

\section{Agriculture insurance products}

115. Crop loan insurance products linked to formal agricultural credit and covering crops and livestock have been initiated by the government. The major banks and insurance companies have developed crop loan insurance programs and products based on the recommendations of the Crop Insurance Task Force in 2008. To promote agriculture loans and protect bank loan portfolios from default, the State Bank of Pakistan launched the CLIS in 2008 for five major crops: wheat, rice, cotton, maize, and sugarcane (para. 46). Crop loan insurance is mandatory for farmers requesting a loan from a financial institution for any of these five crops. However. it is noteworthy that around $50 \%$ of borrowing is from the informal arthis (para. 45). This implies that CLIS covers only a fraction of total national output of the relevant crops. For example, the industry's crop loan premium income of PRs0.5 billion (Insurance Association of Pakistan, 2016) translates to a sum assured of PRs40 billion (at average premium rate of $1.25 \%$ of sum assured), a small fraction of the crop production of PRs2,625 billion (State Bank of Pakistan 2017a, Table 1). Obviously, the voluntary uptake of crop insurance products not linked to credit is meager.

116. Under the CLIS, banks collect the insurance premium on behalf of participating insurers. Aggregate liability of the insurance companies is limited to $300 \%$ of premiums. The government determines events leading to claims payments based on the declaration of a calamity by the Revenue Department and subsequent overall and specific farm surveys by the relevant insurance company. Identified losses of up to $25 \%$ according to the sample fields surveyed are self-insured (i.e., no claim); identified losses of $25 \%$ to $50 \%$ generate payouts equivalent to $50 \%$ of outstanding loans; and identified losses in excess of $50 \%$ generate payouts equivalent to the full outstanding loan. The CLIS premium rates are transacted between $1 \%$ and $2 \%$ of the sum insured (Table 5). Stop-loss reinsurance cover is placed by insurers with international reinsurers. The CLIS covers excessive rains, flood, drought, hailstorms, frost, crop-related viral and bacterial attacks, and pest attacks. In CLIS' early years of operation, loss ratios were approximately 50\% (i.e., from 2009 to 2011 premiums collected were $\$ 20$ million, claims $\$ 10$ million), despite major floods in 2010 (Thanvi 2013). It is likely that the major coverage area of the CLIS during these years was in Punjab, where crop losses owing to the floods were lower than in other parts of the country.

${ }^{60}$ Insurance Association of Pakistan. http://www.iap.net.pk/.

${ }^{61}$ Segregated business category-wise data of disaster insurance is not available with the SECP or Insurance Association of Pakistan.

${ }^{62}$ Separate data on disasters is not available. 
Table 5: Premium Rates on Agricultural Insurance (\% of sum insured)

\begin{tabular}{lccc} 
& $\begin{array}{c}\text { Lowest } \\
\text { Rate }\end{array}$ & $\begin{array}{c}\text { Highest } \\
\text { Rate }\end{array}$ & $\begin{array}{c}\text { Approx. } \\
\text { Average Rate }\end{array}$ \\
\hline $\begin{array}{l}\text { Crop Loan Insurance Scheme (fully government subsidized) } \\
\text { Livestock Loan Insurance Scheme for banks (fully government } \\
\text { subsidized) }\end{array}$ & 2.0 & 2.0 & 1.25 \\
$\begin{array}{l}\text { Crop Insurance (market driven, not subsidized) } \\
\text { Livestock Insurance (market driven, not subsidized) }\end{array}$ & 3.0 & No significant market \\
\hline
\end{tabular}

Source: State Bank of Pakistan (2017b).

117. The Livestock Loan Insurance Scheme of 2013 is an indemnity-based scheme. This scheme covers the financing banks' risk of loan delinquency arising from livestock mortality (including death due to disasters), permanent total disability, and theft of animals. The scheme has many similarities with the CLIS: premium rates are capped (Table 5), distribution is restricted to the formal bank livestock loan process, and subsidy transfers are administered by State Bank of Pakistan. The central government subsidizes the insurance premium for small farmers, defined as farmers having up to 20 cows or buffaloes and 50 fattening cattle. The scheme premium rates range between $3 \%$ and $4 \%$ of the sum insured, i.e. closer to the upper band (Table 5). The sum insured is restricted to the outstanding loan amount. The maximum sum insured is PRs5 million per borrower, and a compulsory deductible of $20 \%$ is applied. Loss ratios were $101 \%$ in 2013 and $97 \%$ in 2014, indicating the reluctance of the insurance industry to sell greater livestock loan insurance scheme volumes at the capped premium rates. In addition, operating costs like tagging and field surveys of animals increase the combined ratio and thus do not make the livestock loan insurance scheme an attractive insurance business proposition. It is estimated that less than $20 \%$ of agricultural insurance premiums (already meager at PRs0.5 billion in FY 2016) are attributed to livestock insurance.

118. In addition to the Livestock Loan Insurance Scheme, private sector insurers offer indemnity-based livestock insurance products (Table 5). Losses due to mortality, permanent total disability and theft are covered by the livestock insurance policy. The products provide value-added services like veterinary and upkeep related advice. However, livestock insurance products are not aggressively marketed due to the meager prospects of generating profits for insurance companies, so have generated limited premium income. Weather-index crop insurance and live weight livestock insurance remain pilots e.g., the Pakistan Microfinance Investment Company subsidized pilots in Soon Valley and Talagang, and livestock insurance in the southeast. Notably, while some interest exists for market driven, non-subsidized livestock insurance, there are no transactions for market driven, non-subsidized crop insurance.

\section{Motor third party liability insurance}

119. Motor third party liability insurance is mandatory, but compliance is low, suggesting low credibility or awareness of insurance. Section 94 of the saved chapter VIII of the repealed Motor Vehicle Act, 1939 (the "1939 Act") stipulates that no person will be allowed use of a motor vehicle in a public place unless there is in force a policy of insurance 
complying with requirements as laid down in Section 95 of this Chapter. According to Section 95 of the 1939 Act, read in conjunction with the Section 5 and Section 6(1) of the Insurance Ordinance, 2000 (the "2000 Ordinance"), only authorized insurer, duly registered with the SECP can issue a policy of insurance against any liability in respect of death or bodily injury to any third person caused by or arising out of the use of an insured vehicle in a public place. While the enforcement and supervision of the 2000 Ordinance is the responsibility of the SECP, the implementation and enforcement of the Motor Vehicle Ordinance, 1965 and the saved chapters of 1939 Act, remain the responsibility of the provincial governments. According to a conservative estimate, about $90 \%$ of vehicles on the roads are not insured at all or not insured with SECP-registered insurers (as required under Section 94). It is common knowledge that unauthorized and fake insurance entities are illegally providing spurious compulsory motor third-party liability insurance certificates to these vehicle owners against a nominal fee. This practice needs to be stopped by stricter enforcement and by an increase in awareness and credibility in insurance protection.

\section{Traditional capital market products}

120. The Karachi Stock Exchange (KSE)-100 index is the leading benchmark index at PSX. The KSE-100 index is a free float adjusted market capitalization weighted index of 100 stocks consisting of top market capitalization companies from each of the 32 sectors and is the most popular index tracking overall prices (SECP 2016b). The KSE-100 Index stood at $32,811.89$ points on 31 December 2015 (SECP 2016b), increasing by $18.10 \%$. to $38,751.60$ points on 16 June 2016. Over during 31 December 2012 to 16 June 2016, the KSE 100 index increased by $412.80 \%$ with a year-on-year compounded return rate of $59.53 \%$.

121. The futures contracts traded in 2016/2017 amounted to PRs3.9 trillion. The futures contracts available as of June 2017 at the Pakistan Mercantile Exchange include varying sizes of gold and silver, red chili, rice, palm olein, crude oil, sugar, I-cotton, wheat, and interest rate contracts. During 2016/2017 Pakistan Mercantile Exchange introduced new future contracts for platinum, Brent crude oil, natural gas and copper, as well as deliverable contracts for paddy super basmati rice, wheat, and red chili. Between 1 July 2016 and 14 June 2017, a total of 3.39 million commodity futures contracts with a combined value of PRs1.3 trillion were traded on Pakistan Mercantile Exchange, about the same traded value as in 2015/2016 but 8\% less in volume (3.7 million contracts). Crude oil was the most traded commodity on Pakistan Mercantile Exchange, with 1.5 million traded lots and gold contracts had the highest traded value with PRs428 trillion. Regarding agriculture, trading volume in red chili contracts surged substantially with 2,200 contracts of red chili valued at over PRs35 million traded through the Pakistan Mercantile Exchange as opposed to 605 contracts traded in FY2015-2016. ${ }^{63}$ Future contracts are useful instruments eliminating price risk for the participants. These instruments usually have limiting clauses in case of force majeure such as major calamities and thus are not seen as DRF instruments but could play an important role in fixing prices of needed goods, such as construction materials, after a disaster.

\footnotetext{
${ }^{63}$ The Nation. 2016. Future contracts worth PRs1.3 trillion traded on PMEX in 2016-17. 13 November. https://nation.
} com.pk/13-Nov-2017/future-contracts-worth-rs1-3tr-traded-on-pmex-in-2016-17. 


\section{Insurance-linked securities}

122. Insurance-linked securities are innovative financial products, used to transfer insurance risk to capital market investors, are not available in Pakistan. ${ }^{64}$ Catastrophe (cat) bonds remain the dominant type of insurance-linked securities globally. Cat bonds are bonds whose coupon and principal payments depend on the non-occurrence of a predefined catastrophic event. Other types of insurance-linked securities include those based on mortality rates, longevity, and medical claim costs. As of 28 December 2017, the global insurance-linked securities issuance for 2017 had risen to $\$ 12.5$ billion, up from $\$ 7$ billion in 2016 , and the outstanding market had increased from $\$ 26.8$ billion in 2016 to $\$ 31$ billion. $^{65}$

123. Typical investors include life insurers' pension funds, mainly adding catastrophe risk into their investments to diversify their exposure to market risk. To a lesser extent, non-life insurers are also investing in insurance-linked securities assuming mortality and morbidity risks. Other institutional investors, including hedge funds searching for yield in a global, low-interest rate environment, are looking at insurance-linked securities favorably.

124. Insurers, reinsurers and governments have been the traditional issuers of ILSs, seeking to download their underwriting exposure into the global capital markets. The Government of Mexico is an active issuer of catastrophe bonds, ${ }^{66}$ both for earthquakes and for hurricanes. It has secured cover through four cat bonds and received payouts under two of them. The costs of those instruments can be as high as $9 \%$ over Libor covering the frequent Atlantic hurricanes of category 4 or higher ( $\$ 210$ million for 2.5 years issued in 2017). The trigger for earthquake protection of the cat bond issued in 2017 was set at magnitude 7.9 or higher for a cost of $4.12 \%$ over Libor. This bond paid out $\$ 150$ million as a consequence of the 2017 Chiapas earthquake (magnitude 8.0). ${ }^{67}$

\subsubsection{Diagnostic and Recommended Actions}

125. The availability of insurance, reinsurance, and capital markets products needs to be enhanced with specific emphasis on personal lines of insurance. The non-life insurance sector has focused mostly on commercial lines of business. Personal insurance demand is low because of low insurance education and awareness, limited outreach of insurance distribution channels, and limited suitable products, among other factors. No notable insurance products have been found for most types of natural hazard, partly due to limited but necessary reinsurance support, ${ }^{68}$ including from the national reinsurer; and also due to the absence of alternate risk transfer mechanisms, such as capital market solutions, for reinsuring the risks not supported by reinsurers. In interviews with stakeholders for the purpose of this assessment, it was learned that reinsurers, including PRCL, are not providing specific natural catastrophe-related reinsurance support, mainly because of lack

${ }^{64}$ For details, see the companion report entitled "Toolkit for Insurance, Reinsurance and Capital Market Solutions for Disaster Risk Financing."

${ }^{65}$ See the Artemis Catastrophic Bond and Insurance-Linked Securities Deal Directory at http://www.artemis.bm/ deal_directory/.

${ }^{66}$ Katie Llanos-Small. 2017. Mexico vs Catbonds: 1-1 Global Capital. 12 October. https://www.globalcapital.com/ article/b154ccrzv0yhcd/mexico-vs-cat-bonds-1-1.

${ }^{67}$ Note that the devastating earthquake in central Mexico in 2017 did not trigger this bond as the magnitude was 7.1, below the trigger level.

${ }^{68}$ The national reinsurer has not been active in disaster reinsurance due to limited data availability on disaster risk. For the same reason, international reinsurers have not supported this type of insurance to date. 
of reliable disaster risk data. Incremental creation of disaster risk insurance awareness, assessment of demand to ascertain insurance product suitability, and provision of adequate reinsurance support would help deliver disaster insurance at all levels. The development of appropriate risk transfer instruments would also support the layered DRF approach (section 1.2).

126. Compliance with motor third-party liability mandatory insurance will be beneficial for Pakistan. This can help promote insurance culture and pave the way to implementation of a potential national-level scheme for disaster risk insurance. High compliance with motor third-party liability insurance will result in countrywide protection against car accidents. Also, the insurance sector will have an important initial volume of retail business with an associated retail insurance sales force, processes to issue individual policies, and positive and an accumulation of widespread experience of insurance, all key steps in expanding the insurance sector.

127. Agriculture group, contract farming, and value-added agriculture supply chain insurance could be significantly further developed. Private sector insurance companies have underwritten a few cases of voluntary agricultural insurance (e.g., livestock farming by Adamjee Insurance and Jubilee Insurance Company). But contract farming and value-added agriculture supply chain insurance products are nonexistent. Group insurance, which has greater understanding of a group's risk profile and shared learning of risk management, is hardly practiced in Pakistan's farming sector. With investments in yield and weather data repositories, risk modelling, technology, distribution, and loss assessment, insurers would be able to offer products on contract farming and value chain insurance.

128. Environmental liability insurance, which is linked with climate change and thus with changing disaster risk, also needs to be developed. Past events affecting the environment (International Tanker Owners Pollution Federation 2003; United Nations Office for Coordination of Humanitarian Affairs; Janjua 2012) - and the subsequent financial impact on the entities responsible for the ensuing damage-have raised awareness of the need for environmental liability insurance. However, it is not well-developed in Pakistan and costs are therefore high and availability of coverage is limited. The introduction of mandatory insurance against environmental damage for industries able to harm the environment would make funds available to repair environmental damage and provide compensation to affected entities and individuals. It would also require the implementation of proper risk management measures to avoid environmental accidents as a precondition to obtain the mandatory liability insurance (Munich Climate Insurance Initiative 2012). It would require certification of proper risk management systems by a credible and knowledgeable institution (to be established in Pakistan). Donors could support this process with a period of assistance, say 5 years, until national capacity is available. The mandatory character of such insurance would lower costs through a wide base and avoid adverse selection as everyone would have to buy the insurance.

129. The government could take advantage of insurance-linked securities as an addition to its set of DRF instruments. While the current sophistication of capital markets and risk ratings do not allow an efficient introduction of insurance-linked securities for catastrophic risks, the government could still take advantage of them via the issue of insurance-linked securities by an AAA-rated entity. Such instruments would include triggers related to disasters affecting Pakistan, such as floods and earthquakes. The government could contribute to the coupon payment in exchange for access to the funds if triggered. 
Precise specifications of the trigger events and associated return periods would need to be defined depending on the risk appetite of global markets and the government's disaster risk protection needs. ${ }^{69}$

\subsection{Social Protection}

\subsubsection{Existing Social Protection Programs}

130. The low-income population is highly exposed to natural hazards and expectations are strong of government protection in disaster. ${ }^{70}$ The government has developed safety nets to achieve at least a basic level of protection for low-income households facing adversity, including as consequence of disaster. The National Disaster Management Authority also provides public assistance to people affected by disasters, including those triggered by natural hazards. $^{71}$

131. The 2014/2015 Pakistan Economic Survey outlines five major social safety net programs executed through specific institutions set for the purpose (Government of Pakistan, 2015). These include the (i) Workers Welfare Fund, (ii) the Employees Old-Age Benefits Institution, (iii) the Zakat Fund, (iv) the Pakistan Bait-ul-Mal, and (v) the Benazir Income Support Programme (BISP). The Workers Welfare Fund and the Employees OldAge Benefits Institution are examples of social protection instruments for members or former members of the formal labor force. The Zakat Fund and the Bait-ul-Mal are examples of social assistance programs, with a broader target group of poorer and more vulnerable individuals who may or may not be part of the formal labor force and, instead, are targeted based on factors such as poverty, income, and vulnerability. The Zakat Fund and the Pakistan Bait-ul-Mal formed the core of Pakistan's social protection or social welfare strategy aimed at the poor for many years. However, social protection only really started to take center stage as a part of social policy relatively recently. Concerns over low coverage, poor targeting, corruption, and fragmentation and duplication of interventions led to the development of the National Social Protection Strategy in 2007. The BISP, established in July 2008, has been at the heart of the execution of this strategy.

132. The BISP is an internationally recognized safety net program. Modern and wellgoverned, it aims to provide a significant share of the poorest population with basic income support and opportunities to escape poverty. The Unconditional Cash Transfers component lies at the core of BISP. Its short-term objective was to cushion the adverse impacts of food, fuel, and financial crisis, but broadly it is to provide a minimum income support package to the chronically poor and those likely to be hurt by economic shocks. It started out in 2008 with PRs1,000/month for the woman of an eligible family, and as of July 2017 stood at PRs18,800/year per family.

\footnotetext{
${ }^{69}$ ADB. Forthcoming. Toolkit for Insurance, Reinsurance and Capital Market Solutions for Disaster Risk Financing. Manila.

${ }^{70}$ Per capita GDP in Pakistan has been just over $\$ 1,000$ since 2006, ( $\$ 1,181.60$ in 2016). Per capita GDP is $9 \%$ of the world's average.

${ }^{71}$ For more details on the ex-gratia assistance, see Appendix 2.
} 
133. BISP has become the single largest unconditional cash transfer program in Pakistan's history. The number of beneficiaries increased from 1.7 million in 2009 to about 5.4 million by January $2018 .^{72}$ In addition, BISP's annual disbursement rose from PRs16 billion in 2009 to PRs102.8 billion in 2017; and between its inception in 2008 and 2017, it transferred PRs515 billion (BISP 2017). The Government of Pakistan provides $90 \%$ of funding, with the rest from the World Bank, the UK Department for International Development, ADB, and the United States Agency for International Development.

134. BISP maintains a national socioeconomic registry of about 27 million households, including 7.7 million with a poverty score of less than 16.17 out of 100, which qualifies them for BISP assistance. With its strong database and refined payment mechanism that directly reaches the most vulnerable, BISP has demonstrated strong outreach and transparency by directly and systematically supporting households. The government has used BISP infrastructure to provide immediate relief through direct compensation to people affected by disasters triggered by natural hazards, as well as victims of bomb blasts and displacements. For more details on BISP's data management and sharing protocols, see Appendix 3.

\subsubsection{Diagnostic and Recommended Actions}

135. With limited insurance capacity in Pakistan, most responsibility for social protection of the low-income population rests with the government. The private insurance sector does not view state-run microinsurance schemes as a viable business proposition but could be incentivized to increase its engagement through creation of transparent publicprivate partnerships led by public-sector insurers.

72 Data available on the BISP website. 


\section{The Rating Summary and Recommended Main Actions}

136. The ideal enabling environment for DRF coincides to a vast extent with the achievable scenario for Pakistan. For this reason, the gap analysis of the current scenario has been carried out against the ideal scenario. Based on the insights gained by applying the $\mathrm{W} \& \mathrm{~W}$ diagnostics tool, no important differences between the ideal scenario and the realistic or achievable scenario were found. Responses from stakeholders regarding the realistic scenario were more by way of providing additional solutions for achieving the ideal scenario, rather than describing limitations that would hinder realization of the ideal. The figure presenting the ratings thus shows only the current situation versus the ideal enabling environment (Figure 6).

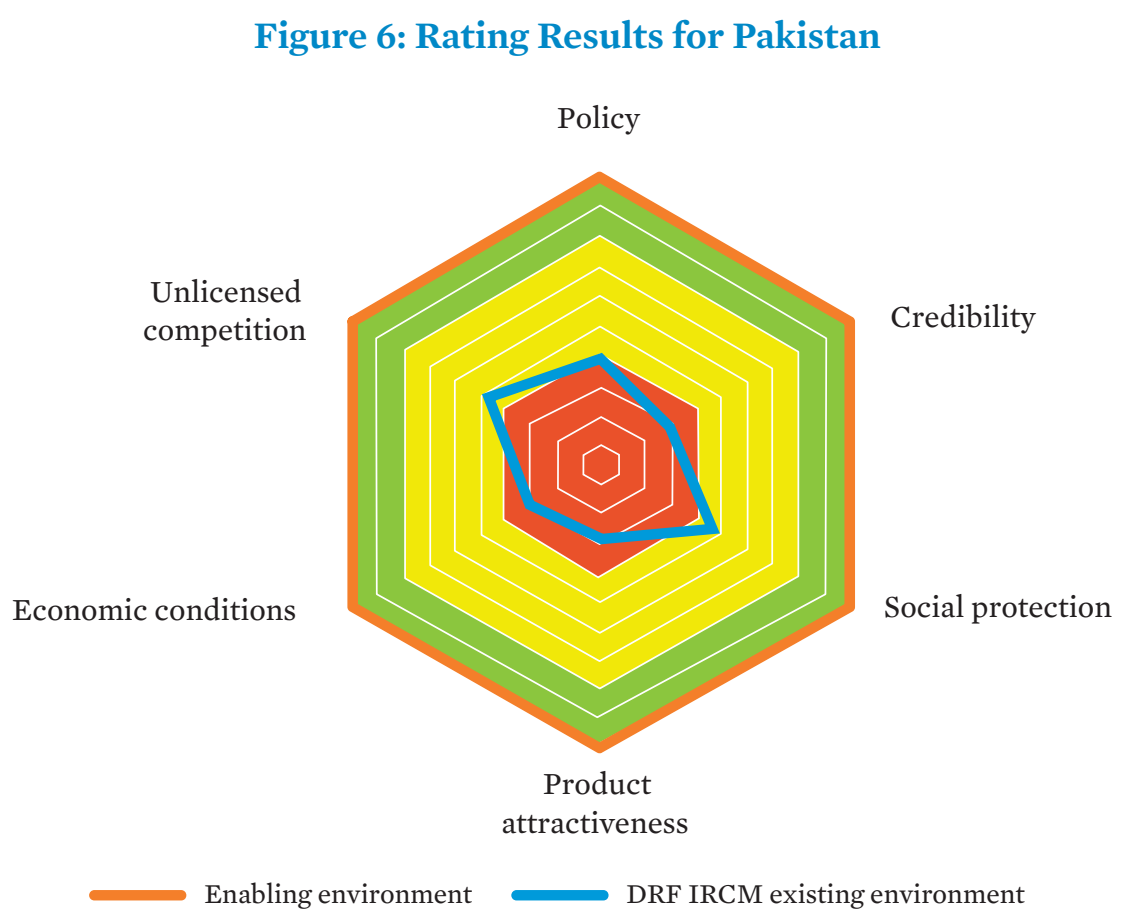

$\mathrm{DRF}$ = disaster risk financing; IRCM = insurance, reinsurance, and capital market. Source: Asian Development Bank. 


\subsection{Gaps in, and Recommendations for, Government Policy}

137. The rating is in the red zone, implying urgent need for action (sections 2.1, 2.2, and 3.1).

138. Main gaps identified:

(i) No comprehensive assessment of disaster risk is readily available for Pakistan.

(ii) A detailed national hazard map (earthquake, flooding, and drought) does not exist, public and private infrastructure and other assets exposed to natural hazards have not been comprehensively quantified, and weather-related data is limited.

(iii) The government has highly limited sovereign risk transfer mechanisms, with only $30 \%$ of public assets insured, and that only during the construction phase.

(iv) Government relies strongly on post-disaster budgetary reallocations and, for major disasters, international assistance to fund post-disaster response efforts.

(v) Federal and provincial governments lack a broader financial strategy to manage the fiscal consequences of disaster.

(vi) Notwithstanding the economic importance of Pakistan's agriculture sector, very few disaster-related insurance, reinsurance, and capital markets solutions are available.

139. Main recommended actions to close the gaps:

(i) Develop a comprehensive national DRF strategy based on detailed modelling of the country's disaster risk.

(ii) Develop a comprehensive disaster risk model and mapping with sufficient granularity to support the development of an effective DRF strategy.

(iii) Develop comprehensive mapping and valuation of provincial and federal governmentowned infrastructure and other assets.

(iv) The Government of Pakistan should consider mandatory disaster insurance for residential property.

(v) The Government of Pakistan should consider establishment of an agricultural insurance pool.

\subsection{Gaps in, and Recommendations for, Credibility in the Insurance Sector and the Capital Markets}

140. The rating is in the red zone, implying urgent need for action (sections 3.2 and 3.3).

141. Main gaps identified:

(i) Insurance is mainly bought by corporations, with less than $15 \%$ of the premium coming from retail insurance (the global benchmark is 50\%).

(ii) Awareness and understanding of insurance is very low. 
(iii) Compliance with the mandatory motor third-party liability insurance is minimal.

(iv) Regulation and supervision has not been assessed by international bodies since 2004 (World Bank).

(v) Past governance issues on insurers have affected the credibility of the sector.

(vi) Underwriting capacity, innovation, and risk management of key insurers is limited.

(vii) There are insufficient numbers of actuaries and surveying companies.

142. Main recommended actions to close the gaps:

(i) Continue to develop customized insurance awareness programs for disaster insurance through public-private partnerships.

(ii) Develop personal lines of disaster insurance, including disaster microinsurance.

(iii) Increase underwriting capacity and risk management of PRCL and NICL to increase their involvement in disaster insurance.

(iv) The SECP should undergo independent regulatory and supervisory assessment against international standards.

(v) Increase the number of actuaries.

\subsection{Gaps in, and Recommendations for, Products}

143. The rating is in the red zone, implying urgent need for action (sections 3.2 and 3.3).

144. Main gaps identified:

(i) Retail insurance products are limited to motor insurance and personal accidents.

(ii) For most types of natural hazard, no notable insurance products are available.

(iii) Contract farming and value-added agriculture supply chain insurance products are practically nonexistent.

(iv) Environmental liability insurance needs to be developed.

(v) Insurance-linked securities are not available.

145. Main recommended actions to close the gaps:

(i) Expand property and liability insurance for individuals.

(ii) Improve insurance products to cover disaster events.

(iii) Advance contract farming and value-added agriculture supply chain insurance products.

(iv) Develop environmental liability insurance.

(v) Introduce insurance-linked securities as a DRF instrument. 


\subsection{Gaps in, and Recommendations for, Social Protection}

146. The rating is in the yellow zone, implying need for action (sections 3.2 and 3.4).

147. Main gaps identified:

(i) Most of the liability for social protection of the low-income population rests with the government.

(ii) The private insurance sector does not view state-run microinsurance schemes as a viable business proposition.

148. Main recommended actions to close the gaps:

(i) Create public-private partnerships led by the public-sector insurers.

(ii) Develop further microinsurance.

\subsection{Gaps in, and Recommendations for, Economic and Other Preconditions}

149. The rating is in the red zone, implying urgent need for action.

150. Main gaps identified:

(i) Per capita GDP is very low and, as such, insurance is a lower priority competing with food, housing, and clothing for a large segment of the population.

(ii) Notwithstanding important progress in the development of the Department of Meteorology capacity, data availability remains insufficient for the development of index insurance.

151. Main recommended actions to close the gaps:

(i) Develop sufficient data for index insurance.

\subsection{Gaps in, and Recommendations for, Unlicensed Competition}

152. The rating is in the yellow zone, implying need for action (section 3.3.1).

153. Main gaps identified:

(i) Around two-thirds of farm sector borrowing is from the informal arthis. This implies that CLIS covers only a fraction of total national output of the relevant crops. 
154. Main recommended actions to close the gaps:

(i) Enhance access to formal agricultural credit by providing easier access and better terms (e.g., lower interest).

(ii) Develop and market agricultural insurance products that can be voluntarily purchased, especially for groups or cooperative. 


\section{APPENDIX 1 \\ Building Code of Pakistan \\ (Fire Safety Provisions 2016)}

1. The Building Code of Pakistan (Fire Safety Provisions 2016) has been issued in exercise of the powers conferred by Section 25 of the Pakistan Engineering Council Act, 1975 (the "PEC Act"). This has been issued by the Governing Body of the Pakistan Engineering Council, with previous approval of the Federal Government (through Ministry of Science and Technology).

2. The Code provides rules for fire prevention, life safety in relation to fire and fire protection of building and structures, and is applicable to the federal and provincial governments, organizations, authorities, both public and private, as notified.

3. Any construction and modification of buildings in violation of Building Code of Pakistan (Fire Safety Provisions 2016) is considered as violation of professional engineering works as defined under the PEC Act.

4. The implementation and enforcement of the Code vest with the Authority Having Jurisdiction (AHJ) within their respective jurisdictions. There is a polarized array of these AHJs, which includes:

(i) Building Control, Housing and Development Authorities

(ii) District Administration

(iii) Tehsil or Town Administration

(iv) Municipal Administration

(v) Station Headquarters (Army, Air Force and Navy)

(vi) Cantonment Administration

(vii) Union Council Administration

(viii) Autonomous Bodies

(ix) Industrial Estates

(x) Directorates of Civil Defense

(xi) Export Processing Zones

(xii) Other Federal/Provincial Authorities as and when notified

5. All relevant AHJs are required to ensure compliance and implementations of the Code and accordingly adopt or amend their relevant regulations, bylaws, or rules if need be. The Code is applicable to both new and existing buildings. While new buildings are required to comply with the Code in an out-right manner, the existing buildings constructed prior to adoption of the Code are required to comply within three years of the notification of the Code. 
6. A person failing to comply with the Code is subject to the penalties in accordance with the regulations of AHJ.

7. This Code is supposed to be reviewed and updated after every 5 years of its notification, on the basis of data and feedback received by the Pakistan Engineering Council. 
APPENDIX 2

\section{Summary on National Disaster Management Authority Guidelines for Minimum Standards of Relief to Be Provided to Persons Affected by Disaster}

1. As per the National Disaster Act of 2010, it is the responsibility of the National Disaster Management Authority to lay down guidelines for "minimum standards of relief to be provided to persons affected by disaster." This document thereby lays down the basic guidelines that will be applicable if a natural calamity of disaster strikes across Pakistan. The governments may modify the rates according to the scale of the disaster and available resources.

2. The ex-gratia relief guidelines are intended to ensure uniformity and streamline the process for assistance. It will address four main areas; death, injury, damage to houses and the restoration of the sources of livelihood.

3. The guidelines provide the basic criteria for declaring emergencies for natural and manmade disasters to more accurately determine the scale of the disasters. All provincial governments and the governments of two autonomous territories are primarily responsible for determining the scale of the disasters as well as the provision of relief. The federal Government will oversee assistance to Federally Administered Tribal Areas (FATA) and the Islamabad Capital Territory (ICT).

4. In some instances, the provincial and federal government may share their relief packages while adhering to the minimum relief limits. Annexure IX of the Guidelines provides details on the minimum cash ex-gratia assistance for affected people with PRs300,000 proposed in case of death due to the disaster. These thresholds may be revised but at the discretion of the governments but keeping in mind that a precedent is not set. All payments will be disbursed manually (pay order/bank draft) or electronically (ATM Debit Card or designated cash outlets) once individuals have been registered and verified.

5. Facilitation Centers will be established to streamline the registration of affected individuals that will be verified either through their National Identity Cards (CNIC) (if available) or NADRA's mobile biometric system for those who have lost their CNIC. The approving authorities, as well as the verification requirements have been outlined in the document to account for the effect on individuals and their properties. A list of required documents for submission along with the relevant application form (Annex I-VIII) for claim have also been provided in the guidelines. The Facilitation Centers will provide a reference number against the submitted claim until assistance has been provided. The Federal Government may also request third party revalidation or re-verification if deemed necessary. False claims will be dealt with as per the National Disaster Management Act 2010.

6. The provincial and regional disaster management authorities will be required to provide daily status reports to National Disaster Management Authority as per the standard formats in these guidelines (Annex X to XV). 
7. The ex-gratia assistance guidelines also list down all the major stakeholders involved in the implementation at various levels as well as their roles and responsibilities. The stakeholders include:

- National Disaster Management Commission-approval and review of all Disaster Management policies

- Ministry of Finance-allocation of federal funds

- National Disaster Management Authority-act as the apex body to oversee implementation of guidelines

- Provincial Disaster Management Authorities-focal organization for implementation of guidelines and ensure transparency and accountability

- Office of Deputy Commissioners/Political Agents-Facilitation Centers, mobilizing beneficiaries, initial verification of claims, coordination with National Database and Registration Authority, Provincial Disaster Management Authorities and provincial governments

- National Database and Registration Authority-technical support for cash transfers 


\section{a \\ BISP Data Management and Sharing Protocols}

\section{The Database}

1. As the key social protection program of Pakistan, BISP maintains a National Socioeconomic Registry (NSER), a database containing information on the socioeconomic status of over 27 million households $(\mathrm{HH})$ across Pakistan except two agencies of federally administered tribal areas.

2. This registry was created as a result of a Poverty Scorecard Survey that BISP developed, first of its kind, in 2010-2011. The Survey covered almost $87 \%$ of the population. The Registry enables BISP to identify eligible households for BISP benefits, including conditional (Waseela e Sehat, Waseela e Taleem, Waseela e Haq, and Waseela e Rozgar) and unconditional (cash transfers) Programs.

3. Additionally, BISP uses data sharing protocols ${ }^{1}$ to allow other social development programs/initiatives to benefit from the data. These initiatives are launched by various provincial governments, donors, international nongovernment organizations, nongovernment organizations, and research organizations. More than 40 other programs/initiatives have benefitted from BISP's data till date. ${ }^{2}$ Most recently, the Prime Minister's National Health Insurance (PMNHI) ${ }^{3}$ and Prime Minister's Interest Free Loan (PMIFL) schemes and Punjab Social Protection Authority used BISP's data, for launching their respective initiatives.

1 Document available at http://bisp.gov.pk/wp-content/uploads/2016/10/SharingForm.pdf.

2 List of organization available at http://bisp.gov.pk/nser/.

3 The Prime Minister's health insurance scheme was launched in December 2015. Initially it was expected to cover around 100 million people across Pakistan, with the budget allocation of PRs9.2 billion. However, as health is a subject which has been devolved to the provinces under the 18th constitutional amendment, so the scheme is supposed to be implemented in partnership with the provincial governments. As per the latest available figures, currently, people who are living in 23 priority districts and earn less than $\$ 2$ a day, according to the BISP's survey, are the beneficiaries of the program. These include people in 4 provinces, two autonomous territories and Islamabad. Free healthcare insurance is being provided to around 1.2 million families, with an average family size of 6.5 people. The second phase of the program, expected to start soon, is said to be going to provide coverage to 3.2 million additional households. All underprivileged Pakistanis who cannot afford hospitalization are eligible to apply online for registration. They are approved after validation with the help of BISP's Poverty Score Card. The biometric enrolment process is done by the local nongovernment organizations in the respective districts, in collaboration with National Database Registration Authority. The enrolled are provided with a magnetic card for accessing free hospitalization from the approved panel of hospitals. Each family is entitled to PRs50,000 for secondary care (common illnesses) and up to PRs250,000 for priority treatment (serious medical ailments) per year. Both private and public hospitals have been empaneled as the designated service providers and are provided interest free funds by the government for the upgrading their facilities. The Ministry of National Health Services Regulation and Coordination is said to have deployed a monitoring system to ensure efficiency and transparency in the program. The State Life Insurance Corporation, a government-owned life insurer, is the sole underwriter of this scheme and it is said that so far, there are no plans to include the private sector insurers in this scheme. 
4. Organizations can make a formal request ${ }^{4}$ to BISP for data that is needed for their programs. The data is flexible enough to cater to accommodating specific needs of the individual Programs. For example, in addition to targeting the poorest, the NSER can also provide list of individuals identified for elderly programs, or for initiatives designed for children or those with a particular illness.

5. Organizations must also specify what the information is being used for research activities or social programs. The extent of use also must be clarified, time period, as well as the means of storage of data. Once BISP is fully satisfied, the data is then confidentially shared and clear agreement between BISP and the organization ensures it is only used for the purpose declared by the receiving stakeholder and will not be leaked to third parties.

\section{Payment Mechanism}

6. Over time, BISP has experimented with various delivery channels for making payments to its beneficiaries. Initially it started out with Pakistan Post where money orders were delivered by a postman at the doorstep of a beneficiary. This had its own set of challenges where pilferage was hard to monitor, and transparency was also lacking. This was followed by the Benazir Smart Card which allowed beneficiaries to collect transferred installment from different franchises in the area. The beneficiary was required to collect the payment personally from the franchise on identification through National Identity Cards (CNIC). Along with this, Mobile Banking Payment Mechanism was also piloted in some districts where beneficiaries were provided with a mobile set and a SIM card and informed of the availability of payment by an Interactive Voice Response Service. Payments were then collected from a franchise using the PIN, also sent via text message.

7. From February 2012 BISP underwent a major change over its payment system by transferring to Benazir Debit Cards. ${ }^{5}$ This mode of payment is based on an ATM card which allows the beneficiary to withdraw payment instalments through the ATM of a bank authorized by BISP. BISP transfers the funds to the bank who in turn distributes to the beneficiaries. This is the latest mode of payment and is being introduced in all districts.

8. Concurrently, improvements to this payment mechanism are being proposed to address practical issues: lost/damaged cards, PIN codes lost, generally a lower literacy level whereby beneficiaries are unable to use the card and end up relying on middlemen who work on commissions. To create a transparent and efficient system, payment through biometric verification system has been proposed. By reducing human involvement in the transaction, the system will automatically become transparent and efficient.

9. Already approved by the board, the New Payment Model $^{6}$ now has various salient features which allows for multiple withdrawal options, through biometrically enabled ATMs, branches, agents and even door step delivery. In addition to this there is fully integrated complaint management as well as online reconciliation and reporting. It also aims to

4 Data request form available at http://bisp.gov.pk/wp-content/uploads/2016/10/DataSharingForm.pdf.

5 To date, $90 \%$ of beneficiaries draw their income support funds through debit card, $1 \%$ through mobile banking and $3 \%$ through biometric mechanisms; $6 \%$ still receive funds through Pakistan Post, due to security and connectivity issues in remote and sensitive areas, including Federally Administered Tribal Areas and Balochistan.

6 See the Benazir Income Support Programme, Unconditional Cash Transfer Programme at http://bisp.gov.pk/ cash-grant/\#1482181305653-c728c00d-9ac. 
incentivize banks to push payments to beneficiaries while bank commissions will be paid after payment delivery to beneficiaries. In addition, the centralized system will allow all data related to withdrawals, claim settlements, service charges to be accessible online.

10. Currently, the New Payment Model stands internally and externally reviewed and vetted, including by the development partners. After piloting, national rollout of the new system is planned for completion by December 2017. 


\section{References}

Asian Development Bank (ADB). 2008. Pakistan: National Agriculture Sector Strategy. Manila.

. 2013. Investing in Resilience: Ensuring a Disaster-Resistant Future. Manila.

. 2014. Operational Plan for Integrated Disaster Risk Management, 2014-2020. Manila.

. 2015. Technical Assistance for Strengthening the Enabling Environment for Disaster

Risk Financing (Phase 1). Manila.

- 2016. Report and Recommendation of the President to the Board of Directors: Proposed Loans, Technical Assistance Grant, and Administration of Grant to Islamic Republic of Pakistan for the National Disaster Risk Management Fund. Manila.

- 2017a. ADB Brief No. 78: Insurance for Micro, Small and Medium-Size Enterprises. Manila.

- 2017b. Climate Change Profile of Pakistan. Manila.

- 2017c. Review of the 2011 Financial Sector Operational Plan. Manila.

—. Forthcoming. Toolkit for Insurance, Reinsurance and Capital Market Solutions for Disaster Risk Financing. Manila.

ADB and the World Bank. 2010. Pakistan Floods 2010 Preliminary Damage and Needs Assessment. Islamabad, Pakistan, November 2010.

- 2014. 2011 Pakistan Floods Preliminary Damage and Needs Assessment. Islamabad, Pakistan, February 2014.

- 2017. Assessing Financial Protection Against Disasters: A Guidance Note on Conducting a Disaster Risk Finance Diagnostic. Manila and Washington, DC.

Associated Press of Pakistan. 2016. SECP Committed to Implement IOSCO Assessment Committee Recommendations. 13 October. http://www.app.com.pk/secp-committedto-implement-iosco-assessment-committee-recommendations/.

Benazir Income Support Programme (BISP). 2017. BISP Progress during PMLN Tenure. August 18, 2017. http://bisp.gov.pk/bisp-progress-during-pmln-tenure-august-18-2017/\#.

Cai, J. 2016. The Impact of Insurance Provision on Household Production and Financial Decisions. American Economic Journal: Economic Policy. 8(2): pp.44-88.

Dorosh, Paul, S. Malik, M. Krausova. 2010. Rehabilitating Agriculture and Promoting Food Security Following the 2010 Pakistan Floods. International Food Policy Research Institute. Discussion Paper 1028. Washington, DC.

Durrani, Ahmad J., et al. 2005. The Kashmir Earthquake of October 8, 2005: A Quick Look Report. MAE Center CD Release 05-04. 
European Commission. 2001. Risk Management Tools for EU Agriculture with a Special Focus on Insurance. Working Document. Brussels.

Food and Agriculture Organization of the United Nations (FAO). 2011. Agricultural Insurance in Asia and the Pacific Region. Regional Office for Asian and the Pacific. Bangkok: FAO.

- 2015. The Impact of Disasters on Agriculture and Food Security. Rome: FAO.

Fonseca, C. 2016. Helping Farmers Understand Index Insurance: Guidelines for Consumer Education Interventions. International Labor Office, Geneva.

Germanwatch. 2015. Global Climate Risk Index 2015. Berlin.

Government of Pakistan. 2000. Insurance Ordinance 2000. Islamabad.

- 2010. National Disaster Management Act of 2010. http://www.ndma.gov.pk/files/ NDMA-Act.pdf, para. 29, sub para. 5.

- 2011. Economic Survey of Pakistan 2010-2011. Islamabad.

- 2014. Federal Budget 2014-15: Budget in Brief. Finance Division, Islamabad.

—_. 2015. Economic Survey of Pakistan 2014-2015. Islamabad.

- 2017a. Economic Survey of Pakistan 2016-2017. Islamabad.

- 2017b. Federal Insurance Ombudsman. Annual Report 2016-2017. Islamabad.

Haq, A., et al. 2013. Who is the "Arthi": Understanding the Commission Agent's Role in the Agriculture Supply Chain. Working paper, International Growth Centre, London School of Economics and Political Science. London.

\section{— . 2015. Platform for Agricultural Risk Management. Rome, Italy.}

Insurance Association of Pakistan. 2016. Insurance Yearbook 2015-2016. Islamabad. Pakistan. http://www.iap.net.pk/download/IAPInsurance Association of Pakistan-Book-2016-17 .pdf.

—. 2017. Insurance Yearbook 2016-2017. http://www.iap.net.pk/download/IAP-Book2016-17.pdf.

Insurance Information Institute. 2015. Presentation on Property and Casualty Insurance Market Update: Trends, Challenges and Opportunities for 2016 and Beyond https:// www.iii.org/presentation/property-and-casualty-insurance-market-update-trendschallenges-and-opportunities-for-2016-and-beyond-120315.

International Organization of Securities Commissions. 2015. Country Review: Islamic Republic of Pakistan - IOSCO Objectives and Principles of Securities Regulation - Detailed Assessment of Implementation. Madrid.

- 2018. Country Review: Islamic Republic of Pakistan IOSCO Objectives and Principes of Securities Regulation - Follow up Report on Assessement of Implementation. Madrid.

International Tanker Owners Pollution Federation. 2003. Tasman Spirit, Pakistan, 2003. 27 July http://www.itopf.com/in-action/case-studies/case-study/tasman-spiritpakistan-2003/.

Janjua, N. Z., et al. 2012. Tasman Spirit Oil Spill in Pakistan - Research Response and Lessons Learned. US National Library of Medicine, National Institutes of Health. Bethesda, Maryland. https://www.ncbi.nlm.nih.gov/pmc/articles/PMC3418438/. 
Llanos-Small, K. 2017. Global Capital October 12, 2017. https://www.globalcapital.com/ article/k4ns4qzwglhq/euroweek-reveals-bond-market-awards-results.

Munich Climate Insurance Initiative. 2012. Insurance Solutions in the Context of ClimateRelated Loss and Damage. http://www.climate-insurance.org/fileadmin/mcii/ documents/20121112_MCII_PolicyBrief_2012_screen.pdf.

Najam, S. 2017. The Case for the Agricultural Sector: Major Challenges and Constraints. Working paper, Shahid Javed Burki Institute of Public Policy at Netsol, Lahore. WP-01-2017. http://www.sjbipp.org/publications/RP/researchpaper/RP-15-17.pdf.

Organization for Economic Co-operation and Development (OECD). 2012. Disaster Risk Assessment and Risk Financing. A G20/OECD Methodological Framework. Paris, France.

Pakistan Reinsurance Company Limited. http://www.pakre.org.pk/ms/Business-Overview .html.

Rao, K. N. 2012. Agricultural Risk Management through Insurance. National Food Security Mission. http://nfsm.gov.in/Meetings_Minutes/NCAER/30_3_KN_Rao-AICAGricultural_Insurance.pdf.

Reyes, C. M., et al. 2017. Agricultural Insurance Program: Lessons from Different Country Experiences. Discussion Paper Series No. 2017-02. Manila: Philippine Institute for Development Studies.

Securities and Exchange Commission of Pakistan (SECP). 2015. SECP Annual Report 2015. Islamabad.

- 2016a. Annual Report 2016. Islamabad.

— . 2016b. Capital Market Development Plan (2016-2018). Islamabad. https://www.secp .gov.pk/document/capital-market-development-plan-2016-18/?wpdmdl=15383.

SECP and World Bank. 2012. Microinsurance in Pakistan-A Diagnostic Study on Demand and Supply. SECP, Islamabad.

Small and Medium Enterprises Development Authority. 2016. State of SMEs in Pakistan. https://www.smeda.org/index.php?option=com_content\&view=article\&id=7:state-ofsmes-inpakistan\&catid $=15$.

State Bank of Pakistan (SBP). 2008a. SBP Task Force Report on Crop Loan Insurance Framework. SBP, Islamabad. https://www.documents.pk/file/State\%20Bank\%20of\%20 Pakistan\%20(State Bank of Pakistan)\%20-\%20State Bank of Pakistan\%20Task\%20 Force\%20Report\%20on\%20Crop\%20Loan\%20Insurance\%20Framework.pdf.

_ 2008b. Standard Operations Procedure for Insurance Scheme. SBP Islamabad. http:// www.sbp.org.pk/press/2008/InsuranceScheme-17-Jul-08.pdf.

- 2015. Task Force Report on Crop Insurance in Pakistan. Islamabad.

—. 2017a. Agricultural Credit Advisory Committee (ACAC) Meeting. Governor's presentation to the Agricultural Credit Advisory on March 7. http://www.sbp.org.pk/ events/ACAC-presentation.pdf.

—. 2017b. Statistical Bulletin, Vol. March, Karachi, Pakistan.

Swiss Re. 2011. Sigma. No 1/2011. Swiss Re, Zurich. 
2016. World Insurance in 2015: Steady Growth Amid Regional Disparities. Sigma No. 3/2016. Zurich.

Thanvi, K. 2013. Crop Loan Insurance in Pakistan. https://agrifinfacility.org/sites/ agrifinfacility.org/files/vberisha/51/AgriFin\%20Webinar\%20_HBL_Presentation.pdf.

United Nations Office for Coordination of Humanitarian Affairs. Tasman Spirit Oil Spill Assessment Report. http://www.unocha.org/sites/dms/Documents/Pakistan.pdf.

Wehrhahn, R. 2010. Insurance Underutilization in Emerging Economies: Causes and Barriers. In C. Kempler, M. Flamée, C. Yang, and P. Windels (eds.). The Global Perspectives on Insurance Today: A Look at National Interest versus Globalization. New York: Palgrave Macmillan.

World Bank. 2010. Government Support to Agricultural Insurance. Washington, DC.

- 2012. Advancing Disaster Risk Financing and Insurance in ASEAN Member States Framework and Options for Implementation. Washington, DC.

. 2013. Fiscal Disaster Risk Assessment-Options for Consideration by Pakistan. Washington, D.C.

. 2014. Financial Protection Against Natural Disasters : An Operational Framework for Disaster Risk Financing and Insurance. Washington, DC.

. 2015a. Agricultural Risk Management in the Face of Climate Change. Agriculture Global Practice, Discussion Paper 09, Group Report no. AUS 5773. Washington, DC.

. 2015b. Financial Sector Assessment Program - Development Module, Washington, DC. http://www-wds.worldbank.org/external/default/WDSContentServer/WDSP/IB /2016/05/10/090224b084313bee/1_0/Rendered/PDF/Mali000Financi0r0 assessment0program.pdf.

—. 2015c. Fiscal Disaster Risk Assessment Options for Consideration. Washington, DC.

- 2017a. Pakistan Development Update. Washington, DC. http://documents.worldbank. org/curated/en/536431495225444544/Pakistan-Development-Update-Spring-2017.

- 2017b. Pakistan Report on the Observance of Standards and Codes: Accounting and Auditing. Washington DC.

Yu, W., et al. 2013. The Indus Basin of Pakistan: Impacts of Climate Risks on Water and Agriculture. Washington, DC: International Bank for Reconstruction and Development. 


\section{The Enabling Environment for Disaster Risk Financing in Pakistan Country Diagnostics Assessment}

This publication seeks to strengthen financial preparedness for disasters in Pakistan. It focuses on insurance and other risk transfer instruments and explores the current application of disaster risk financing solutions by the government, businesses, and individual households; related demand and supply constraints; and opportunities for improvement. This is one of a series of country diagnostics assessments that used a common methodology to determine the state of the enabling environment for disaster risk financing.

\section{About the Asian Development Bank}

ADB is committed to achieving a prosperous, inclusive, resilient, and sustainable Asia and the Pacific, while sustaining its efforts to eradicate extreme poverty. Established in 1966, it is owned by 67 members48 from the region. Its main instruments for helping its developing member countries are policy dialogue, loans, equity investments, guarantees, grants, and technical assistance. 